\title{
TGF- $\beta 1$ affects the renal cancer miRNome and regulates tumor cells proliferation
}

\author{
KAROLINA HANUSEK*, BEATA RYBICKA*, PIOTR POPŁAWSKI, ANNA ADAMIOK-OSTROWSKA, \\ KATARZYNA GŁUCHOWSKA, AGNIESZKA PIEKIEŁKO-WITKOWSKA and JOANNA BOGUSŁAWSKA
}

\author{
Department of Biochemistry and Molecular Biology, Centre of Postgraduate Medical Education, 01-813 Warsaw, Poland
}

Received October 20, 2021; Accepted January 19, 2022

DOI: $10.3892 /$ ijmm.2022.5108

\begin{abstract}
TGF- $\beta 1$ is a pleiotropic cytokine that can either promote or inhibit cancer development and progression. It was previously found that TGF- $\beta 1$ can regulate the expression of several microRNAs (miR or miRNA) involved in the progression of renal cell carcinoma (RCC). Therefore, the present study aimed to analyze the effects of TGF- $\beta 1$ on the global RCC miRNome. It was found that TGF- $\beta 1$ can regulate a complex network consisting of miRNAs and mRNAs involved in RCC transformation. In particular, TGF- $\beta 1$ was revealed to regulate the proliferation of RCC cells while concomitantly modifying the expression of oncogenic regulators, including avian erythroblastosis virus E26 (V-Ets) oncogene homolog-1 (ETS1). In addition, TGF- $\beta 1$ was demonstrated to regulate the expression of a number of miRNAs including miR-30c-5p, miR-155-5p, miR-181a-5p and miR-181b-5p. By contrast, TGF- $\beta 1$ reciprocally modified the expression of genes encoding TGF- $\beta 1$ receptors and SMADs, indicating a novel regulatory feedback mechanism mediated through the miRNAs. These data suggested that ETS1 served different roles in different subtypes of RCC tumors, specifically by functioning as an oncogene in clear cell RCC while as a tumor suppressor in papillary RCC.
\end{abstract}

Correspondence to: Professor Joanna Bogusławska or Professor Agnieszka Piekiełko-Witkowska, Department of Biochemistry and Molecular Biology, Centre of Postgraduate Medical Education, 99/103 Marymoncka, 01-813 Warsaw, Poland

E-mail: joanna.boguslawska@cmkp.edu.pl

E-mail: apiekielko@cmkp.edu.pl

${ }^{*}$ Contributed equally

Key words: TGF- $\beta 1$, renal cell cancer, microRNA, microRNA-155-5p, microRNA-125b-5p, microRNA-30c-5p, microRNA-181a-5p, microRNA-181b-5p, proliferation, bone morphogenetic protein receptor type 2, avian erythroblastosis virus E26 (V-Ets) oncogene homolog-1

\section{Introduction}

Renal cell carcinoma (RCC) is the commonest subtype of kidney malignancy affects 300,000 patients annually worldwide, contributing to the mortality of 100,000 (1). In particular, $80 \%$ RCC cases are diagnosed as the clear cell renal cell carcinoma (ccRCC) subtype, which is the most aggressive and therapy-resistant malignancy of the kidney. The prognosis for patients diagnosed with early-stage RCC is typically superior, since they can be treated efficiently with tumor resection. However, 25-30\% patients with RCC present with metastatic disease at diagnosis, while a further $25 \%$ develop metastasis at later RCC stages (2). Metastatic RCC is typically treated using targeted therapeutic strategies involving tyrosine kinase inhibitors, including sunitinib and sorafenib, monoclonal antibodies aiming to attenuate angiogenesis, such as bevacizumab, inhibitors of the mTOR pathway, including everolimus and temsirolimus or immune checkpoint inhibitors, including nivolumab and ipilimumab. However, the majority of patients will, develop resistance to these therapies aforementioned even if they were primarily responsive, leading to disease progression and mortality $(1,3)$. Key molecular features of ccRCC are inactivation of the tumor suppressor von Hippel-Lindau protein, along with mutations in polybromol,SET-domain containing 2 histone lysine methyltransferase, BRCA-associated protein 1, lysine demethylase 5C and MTOR (4,5), as well as metabolic alterations, including the Warburg effect, disturbances in the pentose phosphate pathway, Krebs's cycle and the metabolism of amino acids and lipids (6). The development and progression of RCC has also been reported to be associated with the altered expression and function of microRNAs (miRNAs). miRNAs are short, non-coding RNAs that can regulate gene expression by interacting with specific miRNA-response elements (MREs) in mRNA transcripts, resulting in their degradation or inhibition of translation $(6,7)$.

TGF- $\beta 1$ is a pleiotropic cytokine, that can regulate a multitude of cellular processes, including proliferation, migration, invasion and metabolism (3). TGF- $\beta 1$ serves as a ligand for the TGF- $\beta 1$ receptor (TGFBR) family of membrane-bound receptors, initiating intracellular signaling cascades with SMAD proteins serving as their main transcriptional regulator downstream. In the kidney, TGF- $\beta 1$ serves an important role by controlling its development and function. Aberrant TGF- $\beta 1$ activation contributes to the excessive deposition of 
extracellular matrix proteins, leading to renal fibrosis and chronic kidney disease (3). It has been frequently reported that TGF- $\beta 1$ serves an ambiguous role in cancer, where it can inhibit its development during the early stages while promoting metastatic spread as the disease progresses (8). In a previous study, it was found that TGF- $\beta 1$ can control the expression of a number of microRNAs in addition to being involved in the regulation of adhesion and migration in RCC cells (9). Therefore, the present study aimed to analyze the effects of TGF- $\beta 1$ on the global RCC miRNome composition and activity. It was found that TGF- $\beta 1$ can regulate a complex network of miRNAs and genes involved in malignant transformation, leading to the changes in RCC proliferation.

\section{Materials and methods}

Culturing and treatment of cell lines. Caki-2 and 786-O cells were purchased from the American Type Culture Collection and KIJ265T cells were kindly donated by Dr John A Copland from Mayo Foundation for Medical Education and Research (Rochester, USA). All cell lines were cultured according to the supplier's protocols and mycoplasma testing was performed for the cell lines used. Treatment of cells with $10 \mathrm{ng} / \mathrm{ml}$ TGF- $\beta 1$ (Thermo Fisher Scientific, Inc.) and/or $10 \mu \mathrm{M}$ of the TGFBR1 inhibitor SB431542 (MilliporeSigma) was preceded by starvation in media containing $1 \% \mathrm{FBS}$ as previously described (9). The conditions of these experiments were selected experimentally (Fig. S1) and/or on the basis of available publications (9-11). For transfections, Caki-2 or $786-\mathrm{O}$ cells were seeded into 96 -well $\left(10^{4}\right.$ cells/well, for BrdU or luciferase assays), 12 -well ( $5 \times 10^{4} /$ well for RNA isolation) or 6 -well $\left(1.25 \times 10^{5} /\right.$ well for protein isolation) plates in complete medium. After $24 \mathrm{~h}$, the cells were transfected with miRCURY LNA microRNA mimics (20 nM) (miR-181a-5p: YM00473040 (5'-AACAUUCAACGCUGUCGGUGAGU-'3); miR-181b-5p: YM00473515 (5'-AACAUUCAUUGCUGU CGGUGGGU-'3); miR-125b-5p: YM00472608 (5'-CGGAUG AGCAAAGAAAGUGGUU-'3); miR-155-5p: YM00472490 (5'-UUAAUGCUAAUCGUGAUAGGGGU-'3); miR-30c-5p: YM00471185 (5'-UGUAAACAUCCUACACUCUCAGC-'3), inhibitors (20 nM) (miR-125b-5p: YI04101864 (5'-UCCCUG AGACCCUAACUUGUGA-'3) or control oligonucleotides (20 nM) (Mimic Negative Control: YM00479902 (5'-UCA CCGGGUGUAAAUCAGCUUG-'3); Inhibitor Negative Control: YI00199006 (5'-TAACACGTCTATACGCCA-'3) (Qiagen, Inc.), anti-avian erythroblastosis virus E26 (V-Ets) oncogene homolog-1 (ETS1) small interfering (si)RNA (Assay ID: s4847, Thermo Fisher Scientific, Inc.), anti-bone morphogenetic protein receptor type 2 (BMPR2) siRNA (Assay ID: s2044, Thermo Fisher Scientific, Inc.) (33 nM) or Silencer Select Negative Control No. 1, using Lipofectamine $2000^{\circledR}$ (Thermo Fisher Scientific, Inc.) at $37^{\circ} \mathrm{C}$ with $5 \% \mathrm{CO}_{2}$ for $24 \mathrm{~h}$, next BrdU, luciferase assay were performed or proteins isolated $48 \mathrm{~h}$ from the end of the transfection and RNA extraction $24 \mathrm{~h}$ from the end of the transfection.

Tissue samples. ccRCC tumor and adjacent non-tumor tissue specimens from 33 patients were retrieved from the local tissue bank deposited at the Department of Biochemistry and Molecular Biology, Centre of Postgraduate Medical
Education (Warsaw, Poland). Tissue samples were collected with written informed consent of each patient with approval of the Bioethical Committee of Centre of Postgraduate Medical Education (approval nos. 18/PB/2012 and 75/PB-A/2014).

Analysis of cells proliferation. Proliferation was examined using Cell Proliferation ELISA, BrdU (colorimetric) kit (Roche Diagnostics, $\mathrm{GmbH}$ ) in accordance with manufacturer's protocols. For BrdU assays, cells were seeded into 96-well plates $\left(10^{4}\right.$ cells/well) for $24 \mathrm{~h}$, before being treated with TGF- $\beta 1$ or vehicle and transfected with siRNAs/miRNA mimics or scrambled control using Lipofectamine $2000^{\circledR}$ (Thermo Fisher Scientific, Inc.) for $72 \mathrm{~h}$.

microRNA array profiling. RNA was isolated from 786-O cells treated with TGF- $\beta 1$ for $48 \mathrm{~h}$ using a GeneMATRIX Universal RNA Purification kit (EURx) according to manufacturer's protocol. The subsequent microarray analysis was performed by Exiqon Services (Exiqon; Qiagen $\mathrm{GmbH}$ ). RNA quality was verified using the Agilent 2100 Bioanalyzer (Agilent Technologies, Inc.). In total, 750 ng RNA was labelled with $\mathrm{Hy} 3^{\mathrm{TM}}$ and $\mathrm{Hy} 5^{\mathrm{TM}}$ fluorescent dyes using the miRCURY LNA $^{\mathrm{TM}}$ microRNA Hi-Power Labeling kit, Hy $3^{\mathrm{TM}} / \mathrm{Hy} 5^{\mathrm{TM}}$ (Exiqon; Qiagen $\mathrm{GmbH}$ ), by following the manufacturer's protocol. The labelled RNAs were then mixed pairwise and hybridized to the miRCURY LNA ${ }^{\mathrm{TM}}$ microRNA Array 7th Generation (Exiqon; Qiagen $\mathrm{GmbH}$ ) according to the protocols in the Tecan HS4800 ${ }^{\mathrm{TM}}$ hybridization station (Tecan, Group, Ltd.). Subsequently, the microarray slides were scanned using the Agilent G2565BA Microarray Scanner System (Agilent Technologies, Inc.) and image analysis was performed using the ImaGeneR 9 miRCURY LNA ${ }^{\mathrm{TM}}$ microRNA Array Analysis Software (Exiqon; Qiagen $\mathrm{GmbH}$ ).

The data obtained, after background correction and normalization using the global locally weighted scatterplot smoothing regression algorithm, were statistically analyzed before miRNAs found to be differentially expressed following TGF- $\beta 1$ treatment were reported by Exiqon (Qiagen $\mathrm{GmbH}$ ). The threshold of detection for each individual microarray slide was calculated as $1.2 \mathrm{X}$ the 25 th percentile of the overall signal intensity of the slide. In total, 1738 miRNA probes with intensities $<20 \%$ of the threshold were removed from the final dataset used for expression analysis. The complete microarray analysis data are provided in Table SI.

Reverse transcription and $q P C R$. For miRNA analysis, cDNA was synthesized using miRCURY LNA Universal cDNA Synthesis kit (Qiagen, Inc.), before qPCR was performed using individual LNA primers (miR-181a-5p: YP00206081; miR-181b-5p: YM00204530; miR-125b-5p: YP00205878; miR-155-5p: YP00204308; miR-30c-5p: YP00204783; miR-28-5p: YP00204322 and miR-103a-3p: YP00204063) with Exilent SYBR Green Master mix (Qiagen, Inc.) according to the manufacturer's protocols as previously described (9). The expression of miRNAs was normalized to that of miR-103a-3p and $\mathrm{miR}-28-5 \mathrm{p}$ and calculated using the $2^{-\Delta \Delta \mathrm{Cq}}$ method (10). In addition, the expression levels of 45 genes in TGF- $\beta 1$-treated 786-O cells were analyzed using Real Time Ready Custom Panels (Roche Diagnostics, $\mathrm{GmbH}$ ) and normalized to those of GAPDH. 
The expression of the individual mRNAs was also analyzed using SYBR-Green I Master (Roche Diagnostics, GmbH) with custom-designed primer pairs (Table SII). This was performed using cDNA synthesized using Transcriptor First Strand cDNA Synthesis kit (Roche Diagnostics, GmbH) for RNA isolated from tissue samples or Revert Aid H Minus FirstStrand cDNA Synthesis kit (Thermo Fisher Scientific, Inc) for RNA isolated from cell lines. The following qPCR conditions were used: initial denaturation at $95^{\circ} \mathrm{C}$ for $10 \mathrm{~min}$ and 45 cycles of $95^{\circ} \mathrm{C}$ for $15 \mathrm{sec}, 57^{\circ} \mathrm{C}$ for $15 \mathrm{sec}$, and $72^{\circ} \mathrm{C}$ for $15 \mathrm{sec}$, followed by melting curve analysis $\left(95^{\circ} \mathrm{C}\right.$ for $5 \mathrm{~min}, 65^{\circ} \mathrm{C}$ for $1 \mathrm{~min}$; continuous reading of fluorescence from $65-97^{\circ} \mathrm{C}$ with $0.11^{\circ} \mathrm{C} / \mathrm{sec}$ ramp rate and five acquisitions per $\left.{ }^{\circ} \mathrm{C}\right)$. A geometric mean of hypoxanthine phosphoribosyltransferase 1 (HPRT1) and $G A P D H$ was the optimal normalizer for the expression of genes in cells treated with TGF- $\beta 1$, while that of $R N A$, $18 S$ Ribosomal $N 1$ and ACTB1 expression was used for the normalization of gene expression in RCC tissue samples. All qPCR experiments were performed in triplicates.

miRNA target site cloning and luciferase assays. Cloning of the miRNA target sites from 3'UTRs of ETS1 and BMPR2 into pmiRGLO vectors (Promega Corporation) and luciferase assays were performed as described previously (9). Sequences of the oligonucleotides used are provided in Table SIII. For luciferase reporter assays, Caki- 2 cells were co-transfected with reaction mix contained $20 \mathrm{nM}$ of miRNA mimics or mimic Negative Control (described earlier), $100 \mathrm{ng}$ of pmiRGLO vectors (with miRNA target sites) and Lipofectamine $2000^{\circledR}$ (Thermo Fisher Scientific, Inc.), at $37^{\circ} \mathrm{C}$ for $24 \mathrm{~h}, 48 \mathrm{~h}$ after transfection luciferase activity was measured using Dual-Glo ${ }^{\circledR}$ Luciferase Assay System (Promega Corporation). Firefly luciferase activity was normalized to Renilla luciferase activity.

Western blotting. Isolation of total protein was performed using the RIPA Lysis and Extraction Buffer (Thermo Fisher Scientific, Inc.) with $0.5 \mathrm{mM}$ PMSF and protease inhibitor cocktail (MilliporeSigma). Proteins concentration was analyzed using Pierce BCA Protein Assay kit (Thermo Fisher Scientific, Inc.). Proteins samples (30 $\mu \mathrm{g}$ per lane) were separated by $10 \%$ SDS-PAGE and transferred onto nitrocellulose membranes and subsequently blocked $\left(8^{\circ} \mathrm{C}\right.$, overnight $)$ in $5 \%$ non-fat milk/TBST (1X Tris-buffered saline, $0.1 \%$ Tween-20 detergent) (MilliporeSigma). Signal detection was performed using SuperSignal West Pico Chemiluminescent Substrate (Thermo Fisher Scientific, Inc.). The expression of proteins was normalized to $\beta$-actin. Catalogue numbers and dilutions of the primary and secondary antibodies used in the present study are as follows: anti-BMPR2, cat. no. ABIN5693167 (Picoband; Boster Bio), 1:1,000; anti-ETS1, cat. no. 14069 (Cell Signaling Technology,Inc.), 1:1,000; anti- $\beta$-actin, 1:10,000, cat.no. ab6276 (Abcam, Inc.) Polyclonal Goat Anti-Rabbit Immunoglobulins/ HRP: P0448 (Dako; Agilent Technologies, Inc.), 1:10,000. Quantification of scanned images was performed with ImageJ version 1.53j software (National Institute of Health, Bethesda).

Bioinformatics analysis. Genes and signaling pathways targeted by miRNAs were predicted using miRSystem (https://mirsystem.cgm.ntu.edu.tw/microrna.org) (11). Only genes identified by $\geq 3$ independent algorithms were selected for further analysis. The expression levels of the selected genes, correlation between their expression levels and TGF- $\beta 1$ expression in addition to the association between their expression and the survival of patients with RCC were evaluated using The Cancer Genome Atlas (TCGA) transcriptomic data of kidney renal clear cell carcinoma (KIRC; $n=535)$ and kidney renal papillary cell carcinoma (KIRP; $n=289)$ cohorts provided by ENCORI v2.0 (https://starbase.sysu.edu.cn/index. php) (12). The expression of proteins were also analyzed using the UALCAN database (https://ualcan.path.uab.edu/ analysis-prot.html) (13) and proteomic data of a KIRC cohort $(n=110)$ Confirmatory/Discovery dataset deposited by the Clinical Proteomic Tumor Analysis Consortium (CPTAC).

Statistical analysis. Data were analyzed using GraphPad Prism 5.00 software for Windows (GraphPad Software, Inc.). Normality of data distribution was determined using the Shapiro-Wilk test. Statistical analysis was performed using unpaired t-test, Wilcoxon matched-pairs signed rank sum, Mann-Whitney, one-way ANOVA followed by Turkey's multiple comparisons or Dunnett's multiple comparison tests as well as Spearman's rank correlation coefficient.

For microarray analysis, to find statistically significant differences in miRNA expression between TGF- $\beta 1$ treated and untreated cells, P-values were calculated using moderated t-statistics, with Benjamini and Hochberg multiple testing adjustment method. The results are shown as mean \pm SEM. $\mathrm{P}<0.05$ was considered to indicate a statistically significant difference.

\section{Results}

Global effects of TGF- $\beta 1$ on miRNAs expression in RCC. Previous studies suggested that miRNAs can regulate the proliferation of RCC cells (14-16). Therefore, the present study first analyzed the global changes in the miRNA expression profile following TGF- $\beta 1$ treatment. A microarray analysis of miRNAs was performed in 786-O cells, which found that TGF- $\beta 1$ treatment altered the expression of 15 microRNAs (Figs. S2 and S3; Table I).

Based on signal intensity (average Hy3 fluorescence intensity, 7.0-14.5) and fold change (minimum, \pm 2.6 ), six microRNAs (miR-181a-5p, miR-181b-5p, miR-181d-5p, miR-125b-5p, miR-155-5p and miR-30c-5p) were selected for further analysis (Table I). RT-qPCR verified that TGF- $\beta 1$ significantly upregulated the expression of miR-181a-5p (by 74\%), miR-181b-5p (by 94\%), miR-181d-5p (by 171\%) and miR-125b-5p (by 85\%), while downregulating the expression of miR-30c-5p and miR-155-5p (by 39 and 40\%, respectively) in 786-O cells (Fig. 1A).

To validate the results of microarray analysis, TGF- $\beta 1$ treatments were repeated using the RCC-derived cell line Caki-2. Consistent with its effect on the 786-O cell line, TGF- $\beta 1$ upregulated the expression of miR-181a-5p, miR-181b-5p and miR-125b-5p in Caki-2 cells (Fig. 1B). However, the upregulation of miR-181d-5p expression by TGF- $\beta 1$ in Caki- 2 cells was not statistically significant (Fig. 1B). In addition, TGF- $\beta 1$ suppressed the expression of miR-155-5p and miR-30c-5p in Caki-2 cells (Fig. 1B). Based on these results, miR-181a-5p, miR-181b-5p, miR-125b-5p, miR-155-5p and miR-30c-5p were selected for further analysis. 
Table I. MicroRNAs differentially expressed in TGF- $\beta 1$ treated vs. non-treated 786-O cells as revealed by microarray analysis.

\begin{tabular}{llcccr}
\hline Probe ID & \multicolumn{1}{c}{ Annotation } & Average Hy3 & $\operatorname{logFC}$ & P-value & FC \\
\hline $\mathbf{4 2 8 6 5}$ & hsa-miR-181a-5p & $\mathbf{8 . 0 2}$ & $\mathbf{0 . 6 1}$ & $\mathbf{3 . 1 0 \times 1 0 ^ { - 3 }}$ & $\mathbf{4 . 0 6}$ \\
28950 & hsa-miR-455-3p & 5.96 & 0.53 & $2.05 \times 10^{-3}$ & 3.37 \\
10952 & hsa-miR-146a-5p & 6.58 & 0.48 & $4.20 \times 10^{-3}$ & 3.00 \\
$\mathbf{1 0 9 7 2}$ & hsa-miR-181b-5p & $\mathbf{7 . 3 6}$ & $\mathbf{0 . 4 6}$ & $\mathbf{2 . 0 5 \times 1 0 ^ { - 3 }}$ & $\mathbf{2 . 8 8}$ \\
$\mathbf{1 6 9 4 0 8}$ & hsa-miR-181d-5p & $\mathbf{7 . 4 6}$ & $\mathbf{0 . 4 5}$ & $\mathbf{4 . 2 0 \times 1 0}$ & $\mathbf{2 . 8 4}$ \\
$\mathbf{3 0 7 8 7}$ & hsa-miR-125b-5p & $\mathbf{7 . 1 3}$ & $\mathbf{0 . 4 4}$ & $\mathbf{1 . 6 9 \times 1 0 ^ { - 3 }}$ & $\mathbf{2 . 7 5}$ \\
11020 & hsa-miR-22-3p & 7.83 & 0.37 & $2.97 \times 10^{-3}$ & 2.35 \\
10928 & hsa-miR-125a-5p & 7.91 & 0.36 & $9.14 \times 10^{-3}$ & 2.31 \\
10306 & hsa-miR-146b-5p & 6.76 & 0.34 & $1.29 \times 10^{-3}$ & 2.21 \\
11052 & hsa-miR-31-5p & 6.07 & 0.34 & $2.97 \times 10^{-3}$ & 2.17 \\
145676 & hsa-miR-30e-3p & 6.07 & -0.22 & $2.87 \times 10^{-2}$ & -1.67 \\
169416 & hsa-miRPlus-A1086 & 6.72 & -0.29 & $2.97 \times 10^{-3}$ & -1.97 \\
17848 & hsa-miRPlus-A1087 & 8.29 & -0.32 & $1.50 \times 10^{-2}$ & -2.08 \\
$\mathbf{4 2 9 2 3}$ & hsa-miR-30c-5p & $\mathbf{7 . 2 7}$ & $\mathbf{- 0 . 3 9}$ & $\mathbf{8 . 9 1 \times 1 0 ^ { - 3 }}$ & $\mathbf{- 2 . 2 9}$ \\
$\mathbf{1 0 9 6 4}$ & hsa-miR-155-5p & $\mathbf{8 . 6 0}$ & $\mathbf{- 0 . 5 0}$ & $\mathbf{2 . 0 5 \times 1 0}$ & $\mathbf{- 3 . 1 8}$ \\
\hline
\end{tabular}

The microRNAs selected for further analysis are in bold.
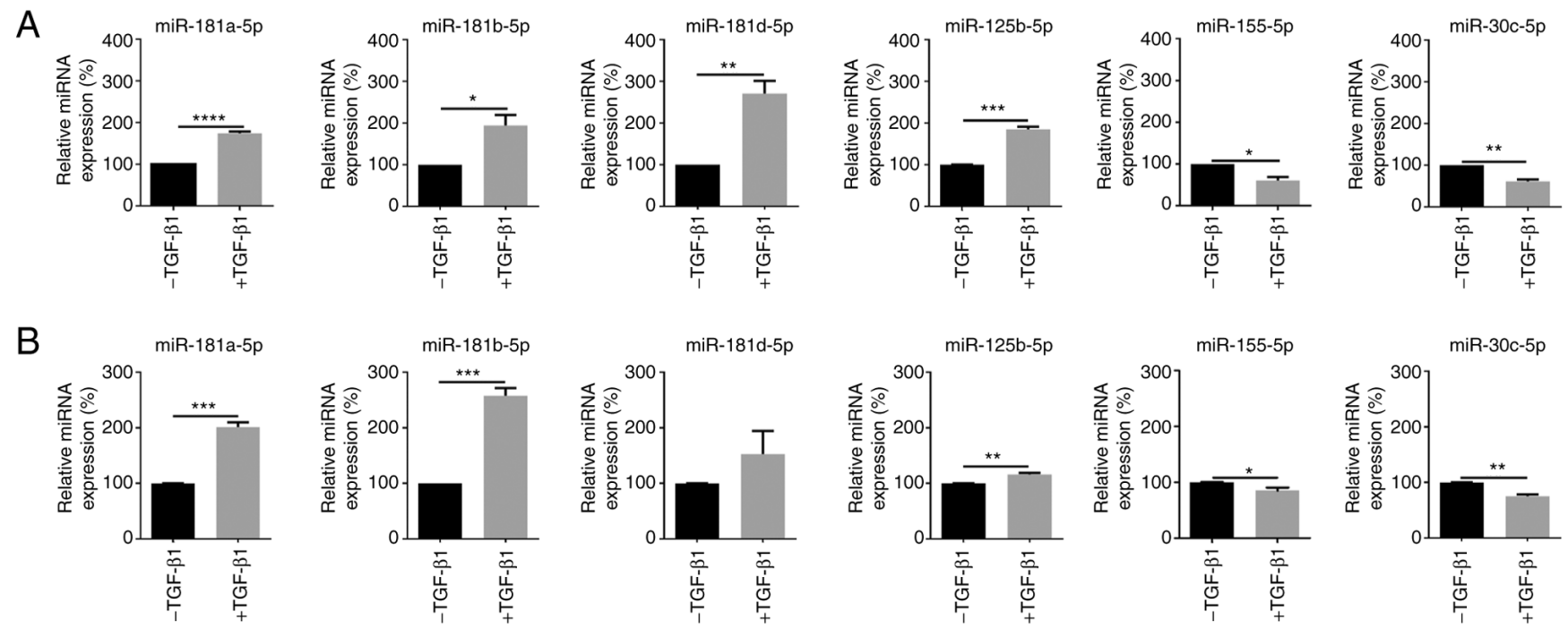

Figure 1. Quantitative PCR validation of miRNA expression in the renal cell carcinoma cell lines. miRNA expression in (A) 786-O and (B) Caki-2 cells following treatment with TGF- $\beta 1$. The plots show results from three independent biological experiment performed in triplicate. ${ }^{*} \mathrm{P}<0.05,{ }^{* * *} \mathrm{P}<0.01,{ }^{* * * *} \mathrm{P}<0.001$, ${ }^{* * * * *} \mathrm{P}<0.0001$. miRNA, microRNA.

Additional analysis of the publicly available transcriptomic data [GSE42718; (17)] of the effects of TGF- $\beta$ on mouse renal tubular cells revealed that consistent with the present study, the expression of mmu-miR-125b-5p and mmu-miR-181b were significantly $(\mathrm{P}<0.05)$ upregulated following TGF- $\beta$ treatment. By contrast, the expression of miR-30c tended to be decreased TGF- $\beta$-treated cells. No statistically significant changes were found for mmu-miR-181a and mmu-miR-155 (Tables SIV and SV).

Effects of TGF- $\beta 1$ on miRNAs are mediated by TGFBR1. To verify if TGFBR 1 can mediate the effects of TGF- $\beta 1$ on target miRNA expression, 786-O cells were cultured in the presence of the TGFBR1 inhibitor. The TGFBR1 inhibitor, was found to reverse the TGF- $\beta 1$-induced expression of miR-181a-5p, miR-181b-5p and miR-125b-5p, while also reversing the suppression of miR-30c-5p expression (Fig. 2). These results suggest that TGFBR 1 can mediate the effects of TGF- $\beta 1$ on these microRNAs. In addition, the expression of miR-125b-5p was observed to be suppressed following addition of the TGFBR1 inhibitor, regardless of the presence of the TGF- $\beta 1$ ligand (Fig. 2). This suggests that TGFBR1 can regulate miR-125b-5p expression in a mechanism independent of TGF- $\beta 1$.

TGF- $\beta 1$-regulated microRNAs can in turn regulate the expression of genes involved in proliferation of RCC cells. To gain additional insight into the molecular mechanism involved in the action of TGF- $\beta 1$ in RCC cells, potential target genes that can 

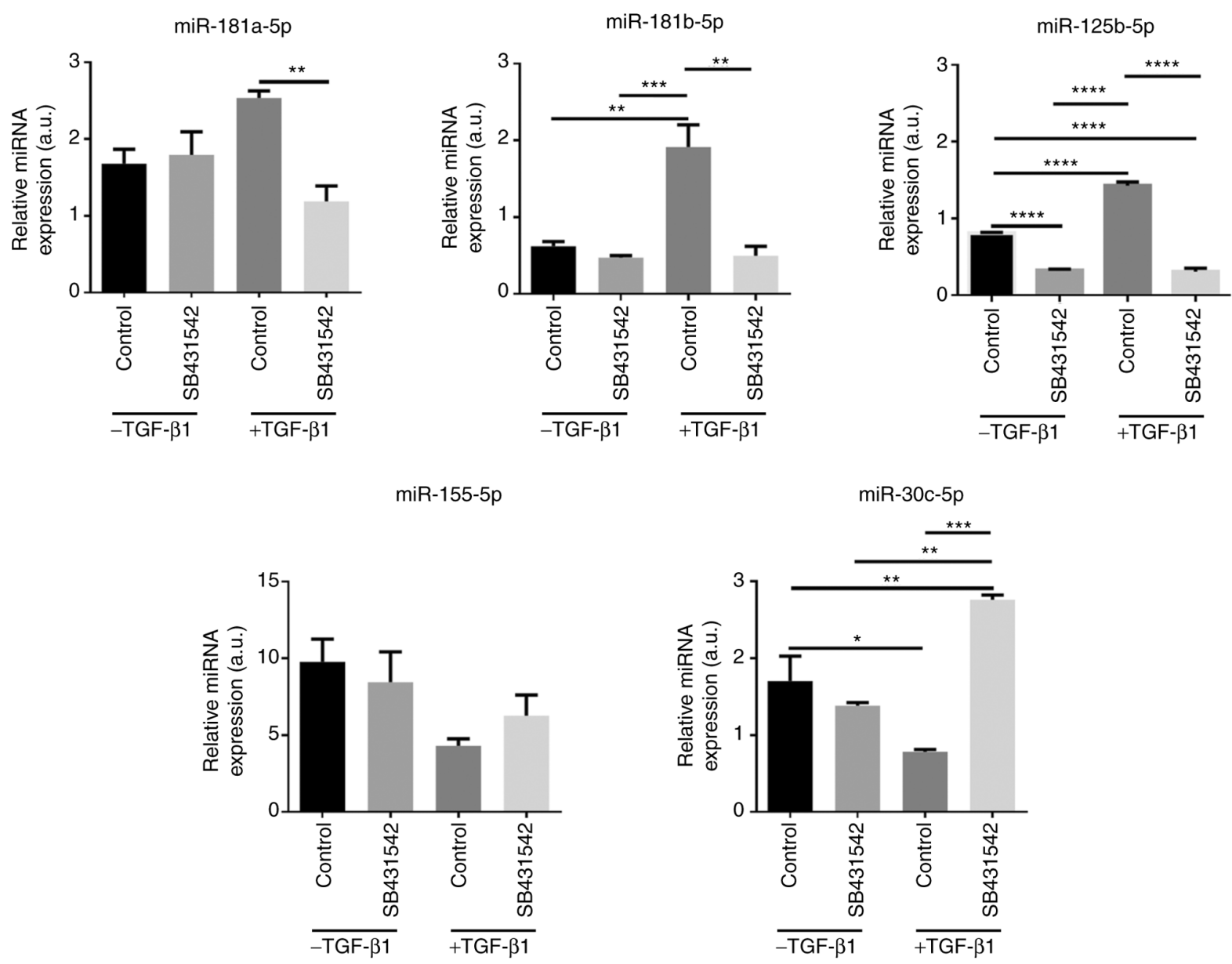

Figure 2. Effects of TGFBR1 inhibition on TGF- $\beta 1$-induced changes in miRNA expression. The plots show the results of qPCR analysis of miRNAs in 786-O cells treated (+TGF- $\beta 1$ ) or not (-TGF- $\beta 1$ ) with TGF- $\beta 1$ in the presence (SB431542) or absence (Control) of TGFBR1 inhibitor for $48 \mathrm{~h}$. Statistical analysis was performed using one-way ANOVA followed by Turkey's multiple comparisons test on data from three independent biological experiments. $\mathrm{P}<0.05$ was considered statistically significant. ${ }^{*} \mathrm{P}<0.05,{ }^{* *} \mathrm{P}<0.01,{ }^{* * * *} \mathrm{P}<0.001,{ }^{* * * * * *} \mathrm{P}<0.0001$. TGFBR, TGF- $\beta 1$ receptor; miRNA, microRNA; a.u., arbitrary units.

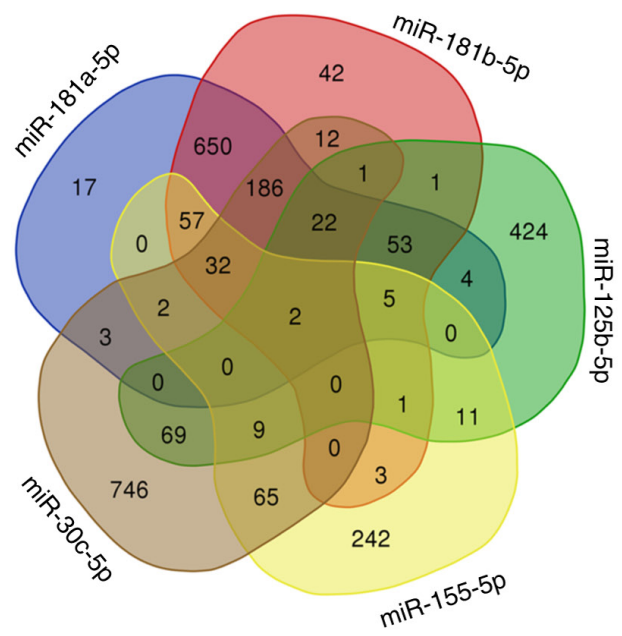

\begin{tabular}{|c|c|c|c|}
\hline TERM & $\begin{array}{l}\text { UNION TARGETS IN } \\
\text { THE TERM }\end{array}$ & $\begin{array}{l}\text { MIRS IN THE } \\
\text { TERM }\end{array}$ & SCORE \\
\hline $\begin{array}{l}\text { NEUROTROPHIN SIGNALING } \\
\text { PATHWAY }\end{array}$ & 45 & 5 & 4.74 \\
\hline $\begin{array}{l}\text { T CELL RECEPTOR SIGNALING } \\
\text { PATHWAY }\end{array}$ & 35 & 5 & 4.15 \\
\hline $\begin{array}{l}\text { TGF-BETA SIGNALING } \\
\text { PATHWAY }\end{array}$ & 32 & 5 & 4.08 \\
\hline AXON GUIDANCE & 43 & 5 & 3.99 \\
\hline LONG-TERM POTENTIATION & 25 & 5 & 3.94 \\
\hline PATHWAYS IN CANCER & 83 & 5 & 3.88 \\
\hline ERBB SIGNALING PATHWAY & 32 & 5 & 3.52 \\
\hline $\begin{array}{l}\text { UBIQUITIN MEDIATED } \\
\text { PROTEOLYSIS }\end{array}$ & 40 & 5 & 3.16 \\
\hline MAPK SIGNALING PATHWAY & 65 & 5 & 2.93 \\
\hline
\end{tabular}

Figure 3. Common genes and pathways targeted by miRNAs downstream of TGF- $\beta 1$-treatment. miRNA-targeted genes and pathways were predicted using miRSystem. Left: Venn diagrams showing the number of common genes predicted to be targets of miRNAs stimulated or attenuated by TGF- $\beta 1$. The names of these genes are shown in Table SVII. Right: signaling pathways predicted to be targeted by miRNAs downstream of TGF- $\beta 1$-treatment. miRNA/miR, microRNA.

potentially mediate the effects of TGF- $\beta 1$-regulated miRNAs were screened using bioinformatics analysis. Specifically, genes and pathways predicted to be targeted by the miRNAs regulated by TGF- $\beta 1$ were screened (Fig. 3; Table SV). All
miRNAs were predicted to regulate analogous signaling pathways (Fig. 3). Specifically, the key predicted that TGF- $\beta 1$-regulated-miRNAs can regulate the TGF- $\beta 1$ signaling pathway, pathways in cancer and the MAPK-signaling 
pathway (Fig. 3). Therefore, the genes potentially involved in these commonly shared miRNA-regulated pathways, in addition to the predicted miRNA target genes related to ERBB, mTOR signaling, regulation of actin cytoskeleton and renal cell carcinoma pathways were selected for further analysis (complete list in Tables SVI-SXIII).

To find possible associations between the predicted miRNA-regulated genes and RCC pathology, their potential impact on the survival of patients with RCC was also analyzed (Table SXIV). In addition, possible RCC-specific changes in gene expression were also assessed using publicly available transcriptomic (ENCORI) and proteomic (UALCAN) databases (Table SXIV). These analyzes resulted in the selection of 42 genes, the altered expression of which were found to associate with poorer patient survival from RCC and/or with TGF- $\beta 1$ expression.

Subsequently, the expression of the 42 selected genes in TGF- $\beta 1$-treated 786-O cells were measured using pre-designed qPCR arrays (Fig. S4). TGF- $\beta 1$ was found to alter the expression of 14 genes (Fig. S4), while the expression of 7 genes (ACVRIC, DCN, FOS, ID4, IFNG, PAK7, PDGFRA and SMADI) were undetectable or below the detection limit ( $>35 \mathrm{Cq}$, data not shown). The results of qPCR arrays were next validated using manual qPCR and primer sets (Table SIV) for the analysis of an independent pool of 786-O cells treated with TGF- $\beta 1$. This analysis revealed that TGF- $\beta 1$ stimulated the expression of $A K T 3, B M P R 2, C B L B$ and ETSI, while inhibiting expressions of PLDI (Fig. 4). There were no changes in the expression of $B C L 2, K R A S$, LAMC1, MAP2K1, MAPK1, PIK3R3, RAPIB, STAT3 and $X I A P$ in $786-O$ cells treated with TGF- $\beta 1$ compared with that in control cells (Fig. 4).

These results aforementioned were also assessed in the Caki-2 cell line (Fig. 5). Consistent with its effects on the 786-O cell line, TGF- $\beta 1$ also increased the expression of ETS1 and BMPR2 in Caki-2 cells (Fig. 5).

MicroRNAs mediate TGF- $\beta 1$-induced changes in gene expression. Subsequently, the potential effects of TGF- $\beta 1$-regulated miRNAs on their target genes were investigated. Firstly, the effects of TGF- $\beta 1$-regulated miRNAs on their predicted MREs in the 3'untranslated regions of selected genes were assessed (Fig. 6A). MREs (Fig. S5) of the selected genes were cloned into luciferase reporter vectors and co-transfected with the respective miRNA mimics into Caki-2 cells. These analyzes confirmed that the MREs of ETS1 were targeted by miR-125b-5p and miR-155-5p, while miR-30c-5p interacted with the MRE of BMPR2 (Fig. 6A). However, none of the miRNAs analyzed suppressed the luciferase activity of vectors encoding mutated MREs (Fig. S6).

Next, the effects of miRNAs on the expression of mRNAs and proteins encoded by the selected genes were tested (Fig. 6B). Significant suppression of BMPR2 mRNA expression was observed following transfection with miR-30c-5p, miR-181a-5p and miR-181b-5p mimics, while ETS1 mRNA expression was inhibited following transfection with miR-125b-5p mimics. Western blot analysis revealed that miR-125b-5p and miR-155-5p mimics transfection suppressed the protein expression of ETS1 (Fig. 6C). No changes in the protein expression of BMPR2 could be observed following transfection with miR-30c-5p, miR-181a-5p (Fig. S7) or miR-181b-5p (data not shown).

These results suggested that the analyzed miRNAs could regulate ETS1 expression either through the degradation of its mRNA by miR-125b-5p and inhibition of its translation by miR-155-5p.

The effects of manipulating the expression of the regulating miRNAs on the TGF- $\beta 1$-mediated regulation of ETS1 expression were next analyzed (Fig. 6D). TGF- $\beta 1$ treatment increased the expression of ETS1, although this effect was higher in the absence of miR-125b-5p or miR-155-5p, where the cells were transfected with their corresponding miRNA inhibitors (Fig. 6D). These results suggest that miR-125b-5p and miR-155-5p partially inhibited the potentiating effects of TGF- $\beta 1$ on ETS1 expression.

TGF- $\beta 1$-regulated microRNAs and their target genes form a regulatory network in $R C C$. To assess the biological context of the identified TGF- $\beta 1$-miRNA-target genes associations, their expression was measured in tissue samples from patients with RCC (Fig. 7). As previously reported (18), TGFB1 expression was enhanced in RCC tumors compared with that in non-tumorous kidney samples. Analysis of the other genes encoding ligands and receptors of the TGF- $\beta$ pathway revealed increased expression levels of TGF- $\beta 3$ and decreased expression levels of TGFBR3 (Fig. 7A). In terms of the TGF- $\beta 1$-regulated miRNAs, expression of miR-125b-5p and miR-30c-5p was significantly decreased, while the expression of miR-155-5p was enhanced in the RCC tumor samples compared with those in the adjacent non-cancerous samples. Expression of miR-181a-5p and miR-181b-5p was not changed in the RCC tumor specimens (Fig. 7B), whereas the expression of BMPR 2 and ETS1 was significantly increased in RCC tumors tissues compared with control samples (Fig. 7C). To analyze the functional associations between the TGF- $\beta 1$-regulated miRNAs and their target genes, the correlation between their expression in the tissue samples from RCC samples was calculated (Fig. 8). A strong positive correlation between the expression levels of genes in the TGF- $\beta 1$ pathway and those of BMRP2 and ETS1 was found (Figs. 8 and S8). Specifically, the expression levels of BMPR2 correlated with those of TGFB2 $(\mathrm{r}=0.74)$, TGFB3 $(r=0.64)$ and TGFBR2 $(r=0.61)$, while ETS1 correlated strongly with TGFB2 $(r=0.57)$, TGFB3 $(r=0.63)$ and TGFBR1 ( $\mathrm{r}=0.52$ ) (Figs. 8 and S8). In addition, strong correlation was found between ETS1 and BMPR2 expression $(\mathrm{r}=0.82)$. In terms of the miRNAs, miR-30c-5p correlated negatively with TGFB1 $(r=-0.48)$, TGFB2 $(r=-0.40)$, TGFB3 $(r=-0.65)$, TGFBR1 $(r=-0.52)$ and TGFBR2 $(r=-0.53)$ (Figs. 8 and S8). These negative correlations between the expression levels of miR-30c-5p and genes in the TGF- $\beta 1$ pathway in RCC tumors were consistent with the observed TGF- $\beta 1$-induced downregulation of miR-30c-5p expression in RCC cells (Fig. 1).

ETS1 regulates RCC cells proliferation in a subtype dependent manner. ETS1 and BMPR2 are known regulators of tumor cells proliferation and survival $(19,20)$. To study the role of these two proteins in the regulation of RCC cell proliferation, Caki-2 and 786-O cells were transfected with anti-ETS1 and anti-BMPR2 siRNAs. It was found that BMPR2 knockdown reduced the proliferation of Caki- 2 cells while increasing 

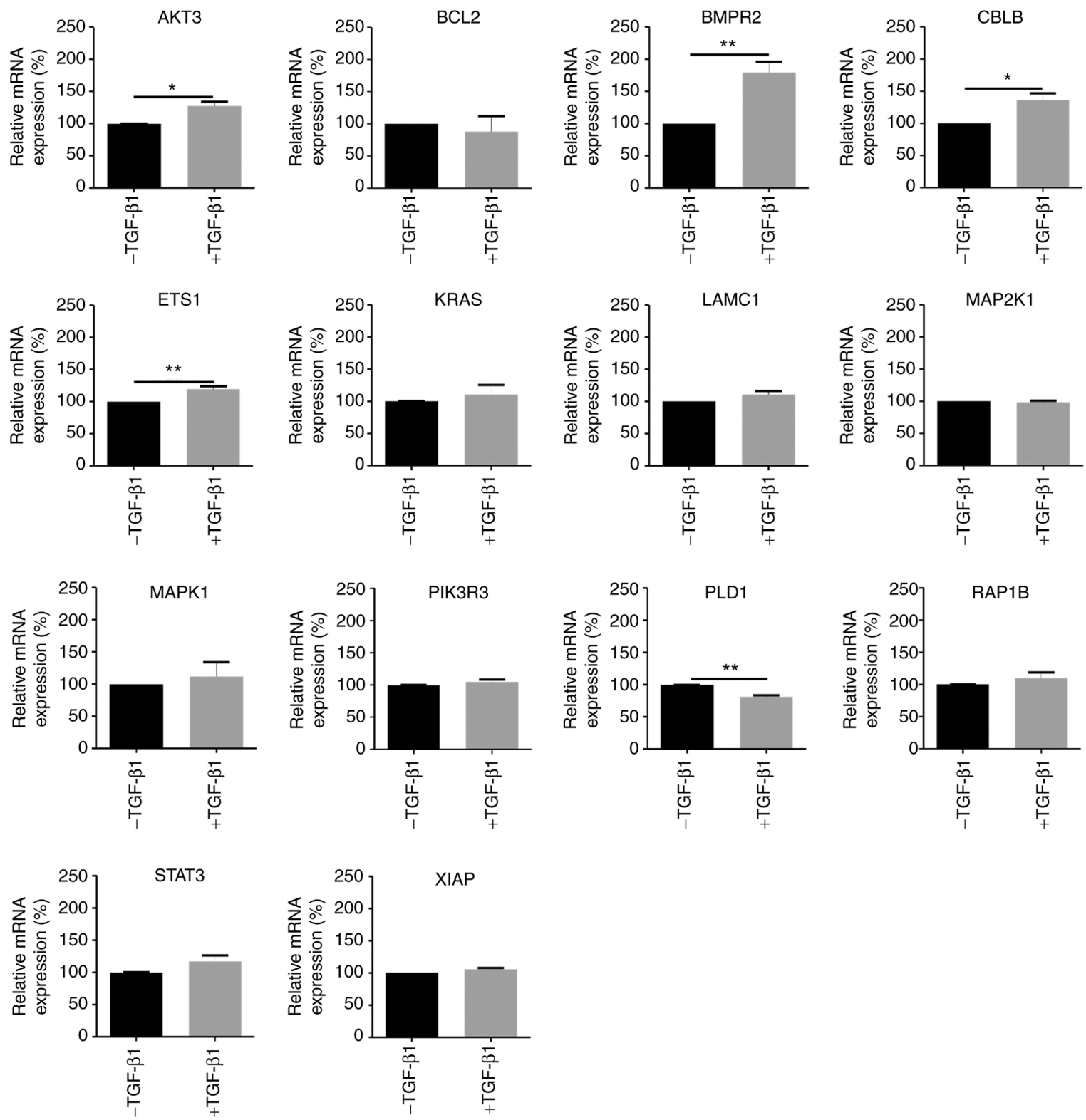

Figure 4. Effect of TGF- $\beta 1$ on the expression of genes predicted to be targets of TGF- $\beta 1$-regulated miRNAs. 786-O cells were treated (+TGF- $\beta 1$ ) or not (-TGF- $\beta 1$ ) with TGF- $\beta 1$ for $48 \mathrm{~h}$, before quantitative PCR analysis was performed to measure gene expression. The plots show the results from three independent experimental repeats. Statistical analysis was performed using unpaired t-test. $\mathrm{P}<0.05$ was considered statistically significant. ${ }^{*} \mathrm{P}<0.05,{ }^{* *} \mathrm{P}<0.01$. miRNA/miR, microRNA; BMPR, bone morphogenetic protein receptor type; ETS, avian erythroblastosis virus E26 (V-Ets) oncogene homolog-1; KRAS, V-Ki-ras2 Kirsten rat sarcoma viral oncogene homolog.
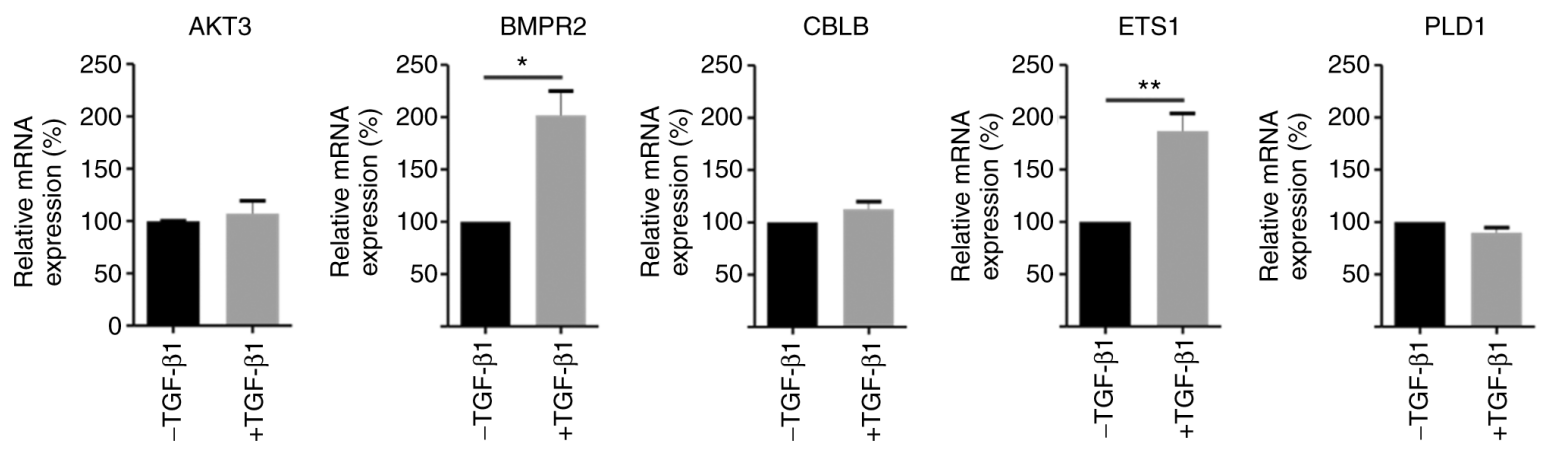

Figure 5. Validation of the effects of TGF- $\beta 1$ effects on the expression of predicted genes targeted by the miRNAs in Caki- 2 cells. Caki- 2 cells were treated (+TGF- $\beta 1$ ) or not (-TGF- $\beta 1$ ) with TGF- $\beta 1$ for $48 \mathrm{~h}$, before quantitative PCR analysis was performed to measure gene expression. The plots show the results of three independent biological experiments. Statistical analysis was performed using unpaired t-test. $\mathrm{P}<0.05$ was considered statistically significant. ${ }^{*} \mathrm{P}<0.05$, ${ }^{* *} \mathrm{P}<0.01$. miRNA/miR, microRNA; BMPR, bone morphogenetic protein receptor type; ETS, avian erythroblastosis virus E26 (V-Ets) oncogene homolog-1; PLD, phospholipase D. 


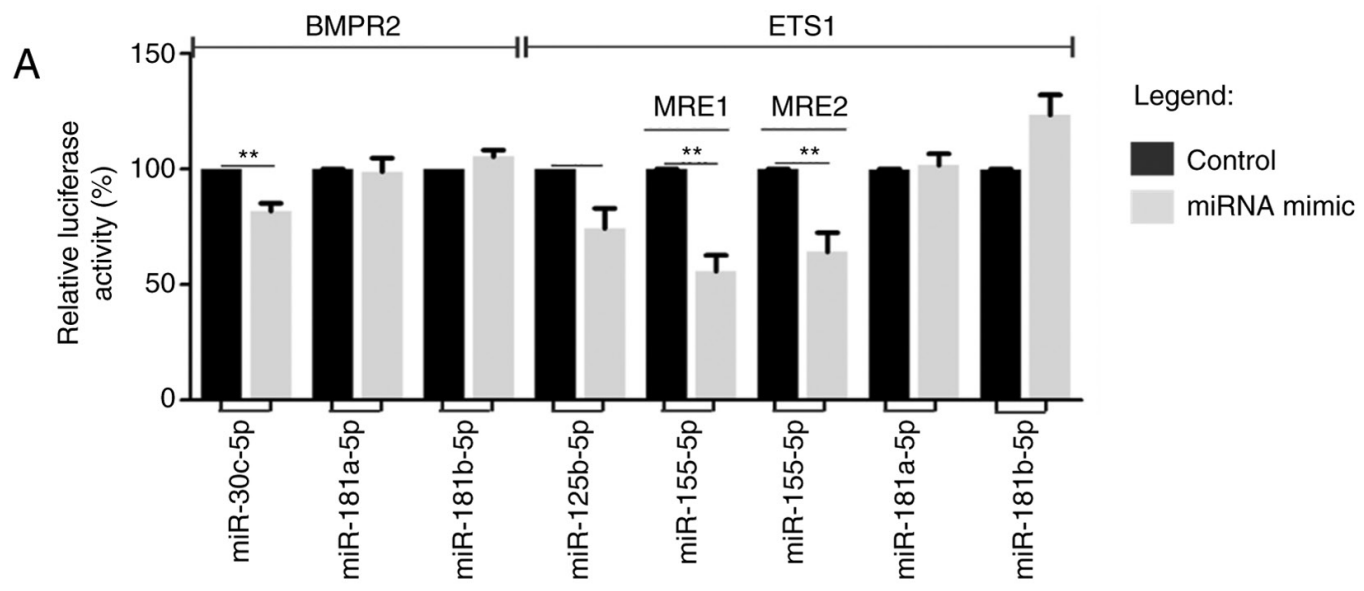

B
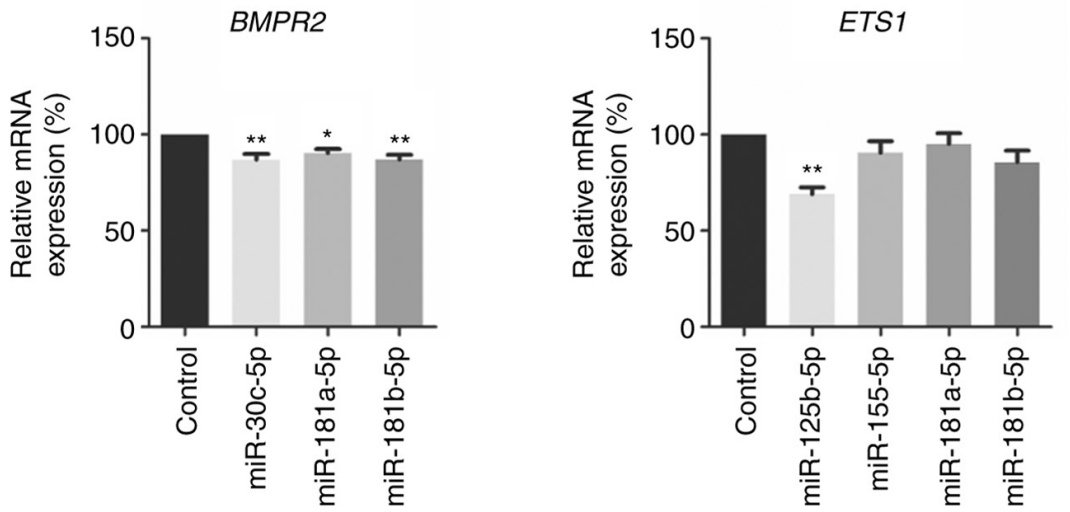

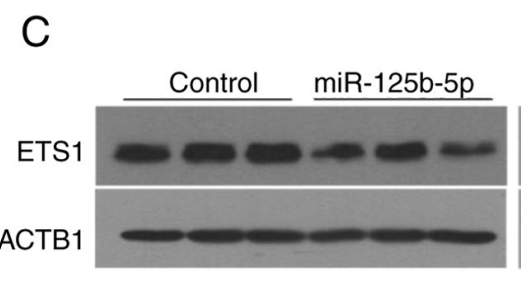

D

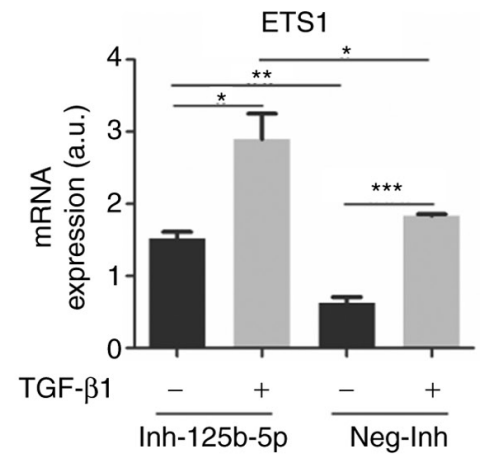

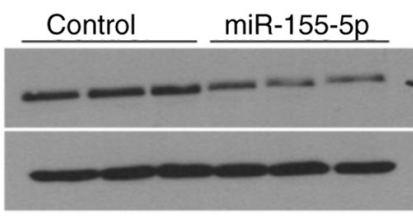

$52 \mathrm{kDa}$

$42 \mathrm{kDa}$

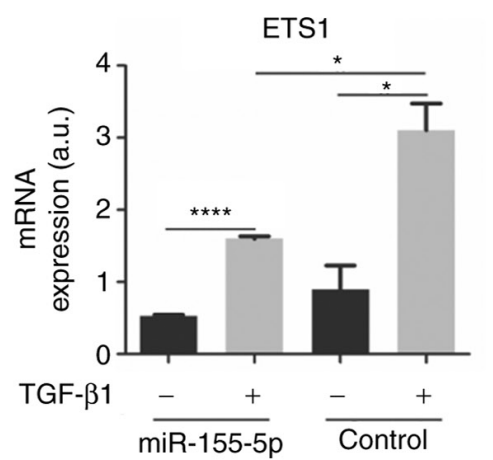

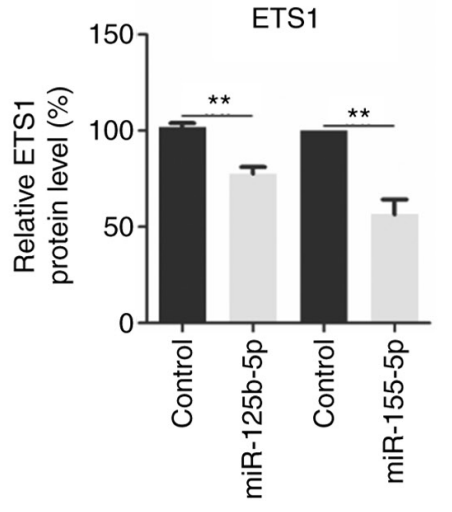

Figure 6. Validation of the association between TGF- $\beta 1$-regulated miRNAs and their target genes in RCC. (A) Plots showing the data of luciferase reporter assays. Caki-2 cells were co-transfected with miRNA mimics or non-targeting control mimics and reporter plasmids encoding the cloned MREs, before luciferase activity was measured. The plots show the results from three independent experimental repeats. The two sets of bar charts for ETS1 and miR-155-5p represent the data from two separate miR-155-5p MREs predicted in the 3'UTR of this gene. (B) The effects of TGF- $\beta 1$-regulated miRNAs on the mRNA expression of the predicted target genes. Caki-2 cells were transfected with miRNA mimics or non-targeting control mimics, prior to quantitative PCR analysis of the predicted miRNA target genes. The plots show the results from three independent biological experiments. Statistical analysis was performed using one-way ANOVA with Dunnett's multiple comparison test. (C) The effects of TGF- $\beta 1$-regulated miRNAs on the protein expression of their predicted targets. Caki-2 cells were transfected with miRNA mimics or non-targeting control mimics, before western blot analysis of target protein expression. Left: Representative western blotting images and a corresponding plot showing changes in protein expression normalized to $\beta$-actin are shown. (D) miR-125b-5p and miR-155-5p inhibited TGF- $\beta 1$-mediated activation of ETS1 expression. Caki-2 cells were transfected with the miR-125b-5p inhibitor and miR-155-5p mimic or their corresponding non-targeting control oligonucleotides. The plots show results from three independent biological experiments performed in triplicates. Statistical analysis was performed using unpaired t-test. $\mathrm{P}<0.05$ was considered statistically significant. ${ }^{*} \mathrm{P}<0.05,{ }^{* *} \mathrm{P}<0.01,{ }^{* * * *} \mathrm{P}<0.001,{ }^{* * * * *} \mathrm{P}<0.0001$. miRNA/miR, microRNA; BMPR, bone morphogenetic protein receptor type; ETS, avian erythroblastosis virus E26 (V-Ets) oncogene homolog-1. 

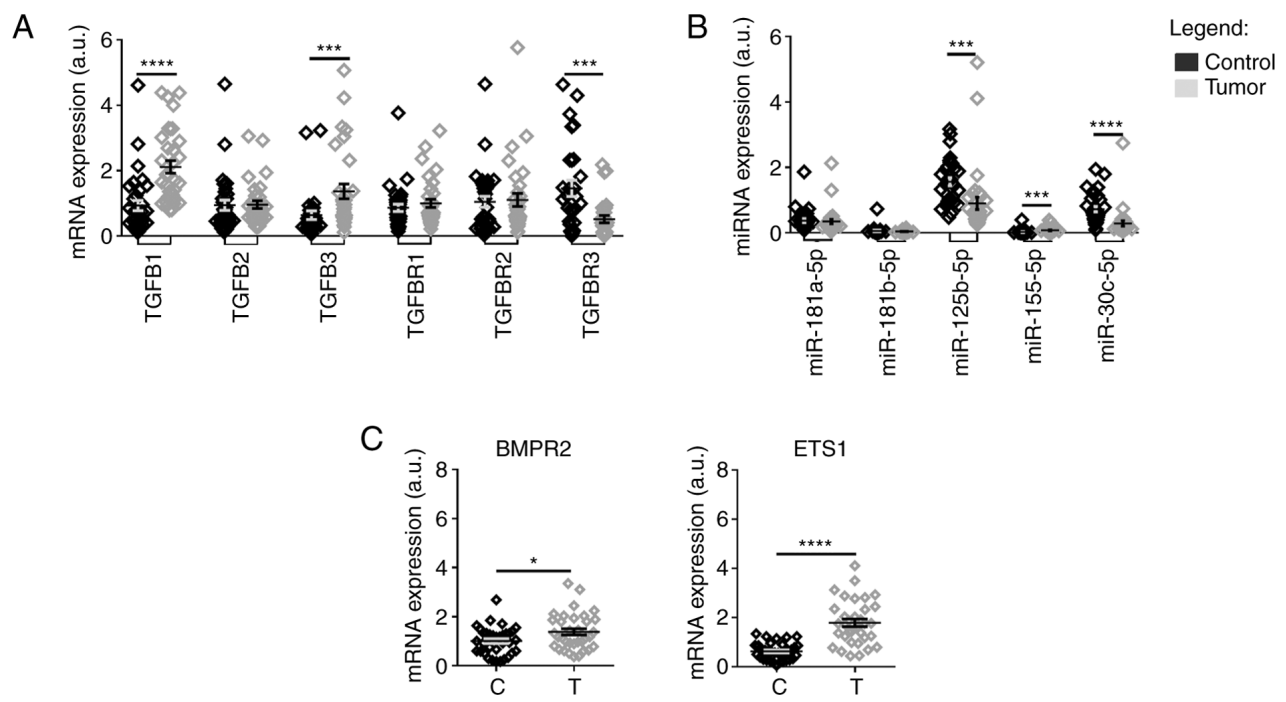

Figure 7. Analysis of the expression profile of genes predicted to be targeted by the TGF- $\beta 1$ pathway. (A) TGF- $\beta 1$-regulated miRNAs and (B) TGF- $\beta 1$-regulated genes in (C) RCC tumor samples. The plots show results of quantitative PCR analysis performed on RCC tumors ( $\mathrm{n}=33$ ) and matched-paired non-tumorous control samples $(\mathrm{n}=33)$. Statistical analysis was performed using Wilcoxon matched-pairs test in $(\mathrm{A})$ and $(\mathrm{B})$ or paired $\mathrm{t}$-test in $(\mathrm{C}) .{ }^{*} \mathrm{P}<0.05 ;{ }^{* * * *} \mathrm{P}<0.001$; ${ }_{* * * * *} \mathrm{P}<0.0001$. miRNA/miR, microRNA; RCC, renal cell carcinoma.

A
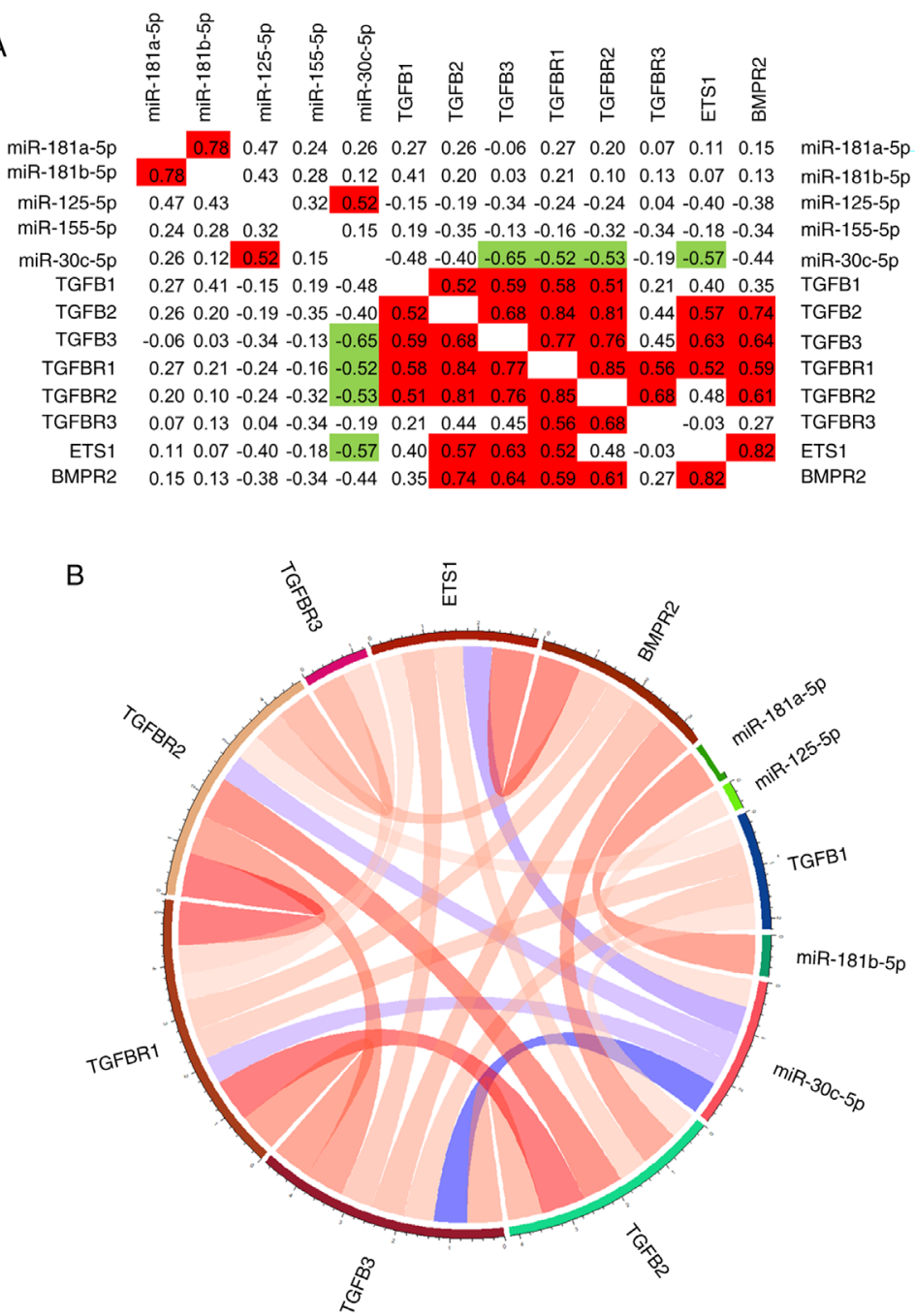

Figure 8. Analysis of associations among the expression levels of genes in TGF- $\beta 1$ pathway, TGF- $\beta 1$-regulated miRNAs and genes in the RCC tissues. Analysis was performed using the control:RCC tumor ratios of expression. (A) Correlation analysis showing the Spearman $\rho$-values. Red represent Spearman $\rho$-values $\geq 0.5$ whereas blue represents Spearman $\rho$-values $\leq-0.5$. P-values are shown in Table SIV. (B) Circular plot showing the strongest positive (Spearman $\rho$-values $\geq 0.5$, red lines) and negative (Spearman $\rho$-values $\leq-0.5$, blue lines) correlations. Thickness of the lines are dictated by the Spearman $\rho$-values (the higher the Spearman $\rho$-value, the thicker the line). miRNA/miR, microRNA; RCC, renal cell carcinoma. 
A

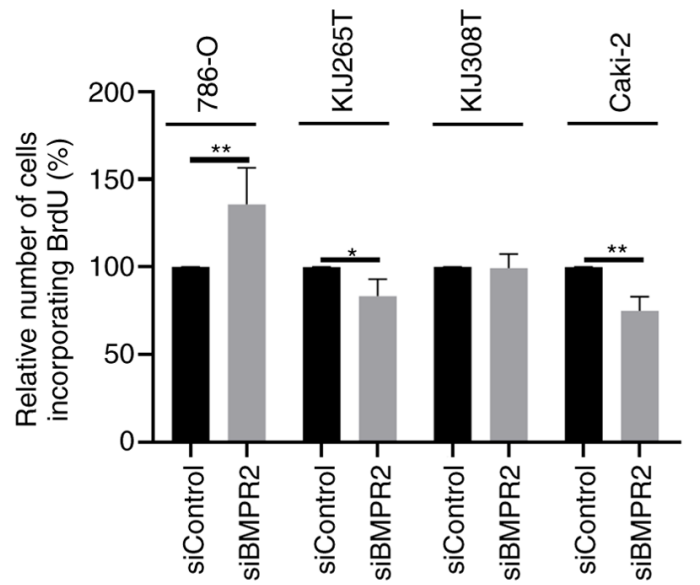

B

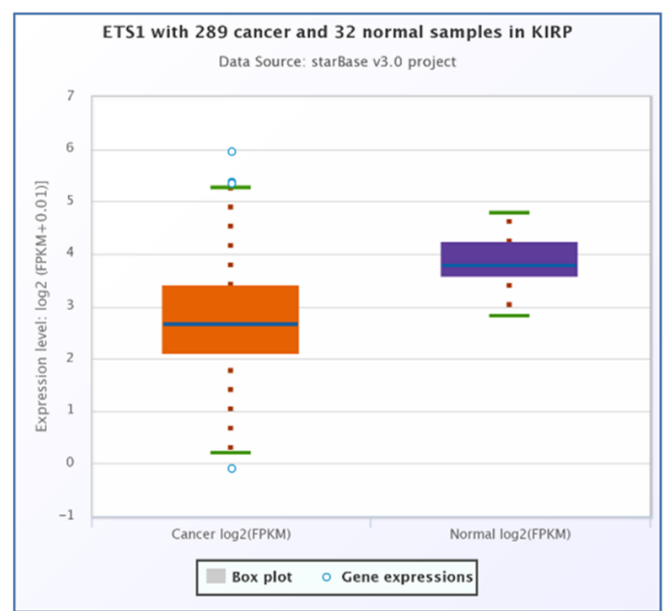

C

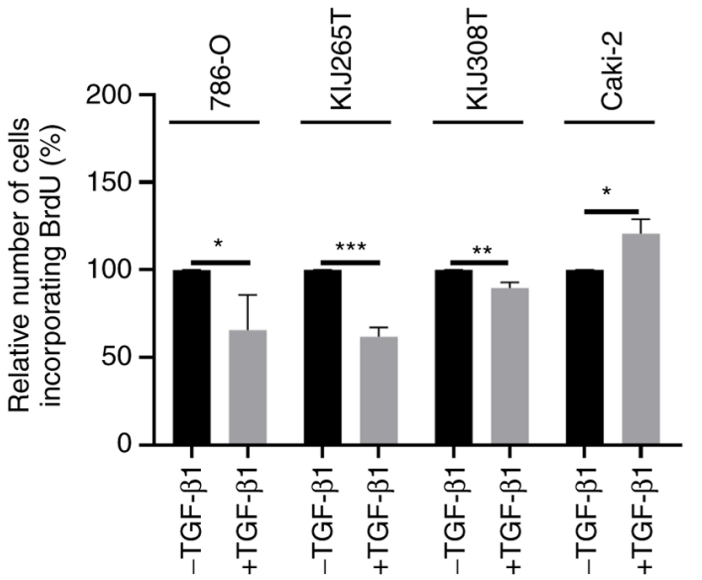

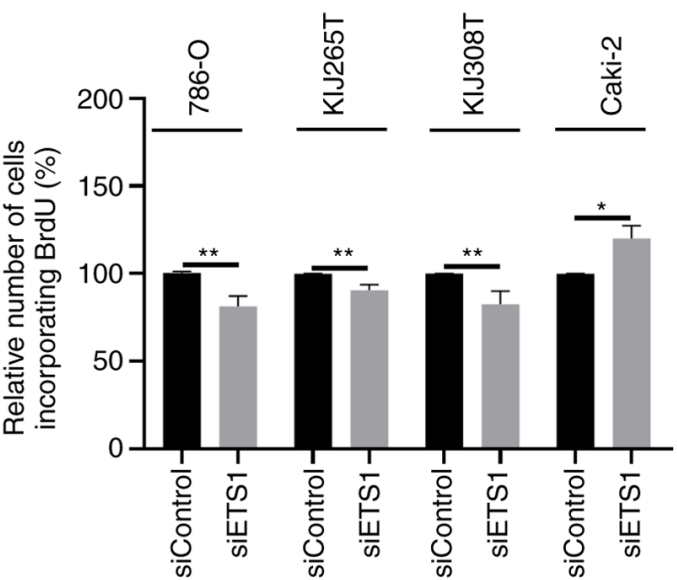
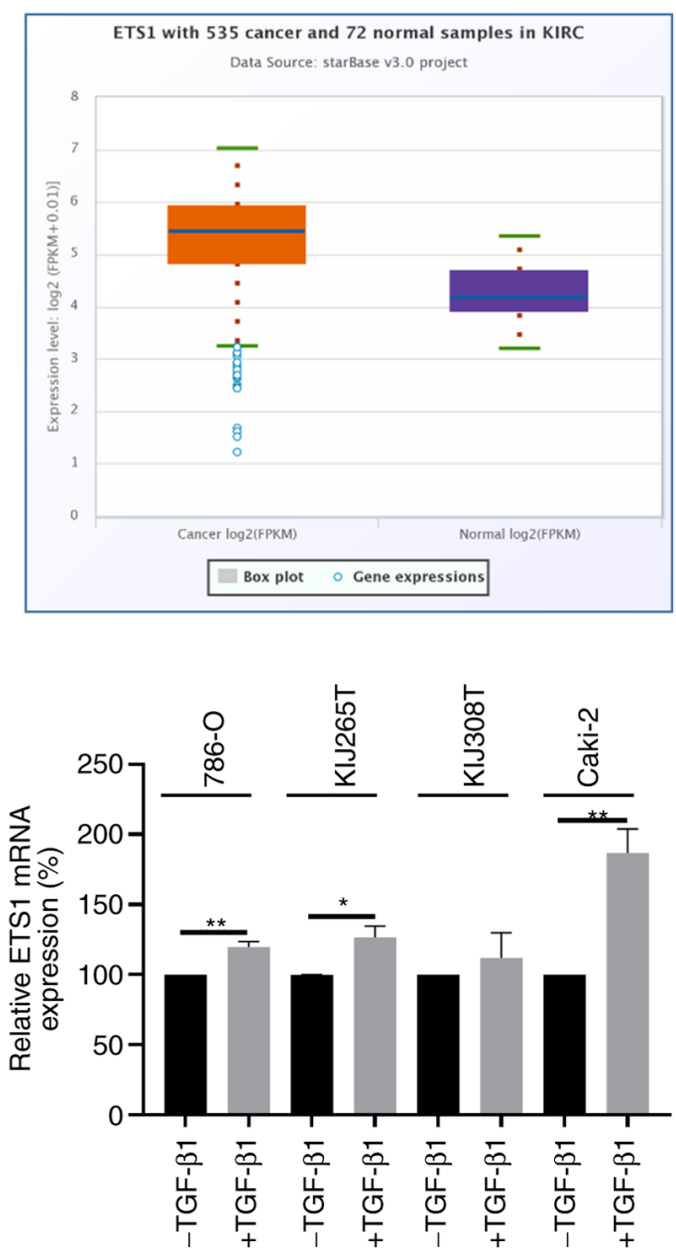

Figure 9. ETS1 regulates RCC proliferation in a RCC-tumor subtype dependent manner. (A) The effects of BMPR2 and ETS1 signaling in 786-O, KIJ265T, KIJ308T and Caki-2 cells. Plots show proliferation of cells analyzed using BrdU incorporation assay after silencing of BMPR2 (left) and ETS1(right). The graphs show mean results of 3 independent biological experiments performed in triplicate. (B) The expression of ETS1 in ccRCC and pRCC cells, the graphs were generated using TCGA transcriptomic data of KIRC $(\mathrm{n}=535)$ and KIRP $(\mathrm{n}=289)$ cohorts provided by ENCORI. (C) Left graph: Proliferation of 786-O, KIJ265T, KIJ308T and Caki-2 cell lines treated (+TGF- $\beta 1$ ) or not (-TGF- $\beta 1$ ) with TGF- $\beta 1$ for $72 \mathrm{~h}$. Right graph: ETS1 expression in 786-O, KIJ265T, KIJ308T and Caki- 2 cell lines treated (+TGF- $\beta 1$ ) or not (-TGF- $\beta 1)$ with TGF- $\beta 1$ for $48 \mathrm{~h}$. Statistical analysis was performed using paired t-test. ${ }^{*} \mathrm{P}<0.05$; ${ }^{* *} \mathrm{P}<0.01$; ${ }_{* * * *} \mathrm{P}<0.001$. ETS, avian erythroblastosis virus E26 (V-Ets) oncogene homolog-1; RCC, renal cell carcinoma; BMPR, bone morphogenetic protein receptor type; ccRCC, clear cell RCC; pRCC, papillary RCC; TCGA, The Cancer Genome Atlas.

the proliferation of 786-O cells. Conversely, silencing of ETS1 expression, which was confirmed on both mRNA and protein levels (Figs. 9A and S9) increased the proliferation of Caki-2 cells while decreasing the proliferation of 786-O cells (Fig. 9A). These results suggest that the proliferation of 786-O cells was inhibited by BMRP2 but activated by ETS1, while in Caki-2 cells these effects were opposite.

The Caki-2 cell line is considered to be of papillary (p) RCC, while 786-O is a ccRCC cell line. To test if the roles of BMPR2, ETS1 and TGF- $\beta 1$ in the regulation of proliferation 
A

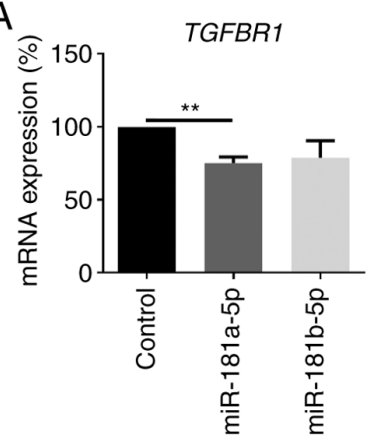

B

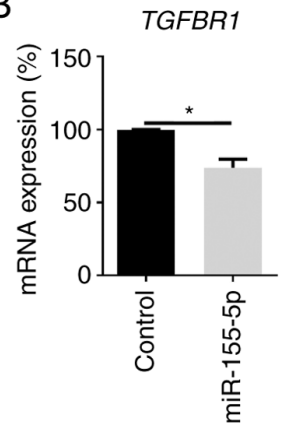

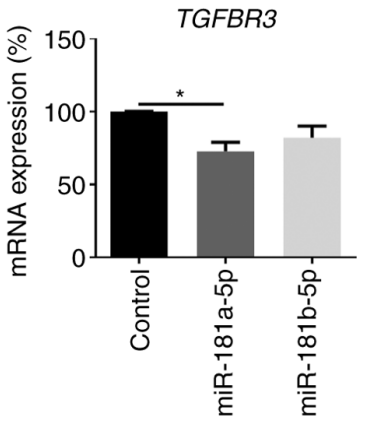

SMAD1

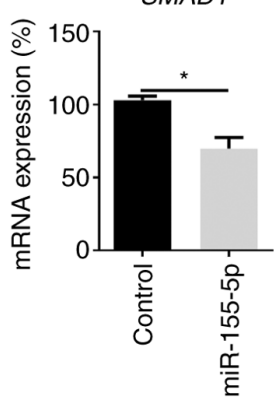

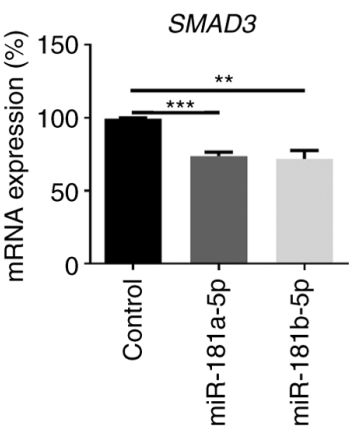

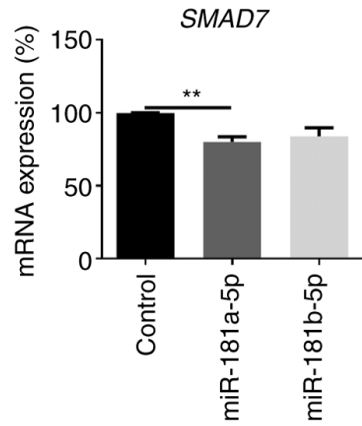

C

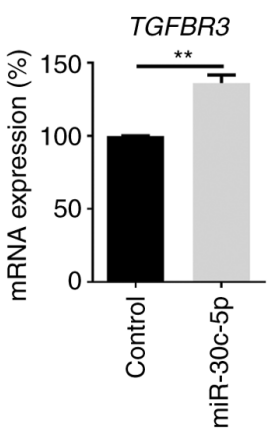

SMAD1

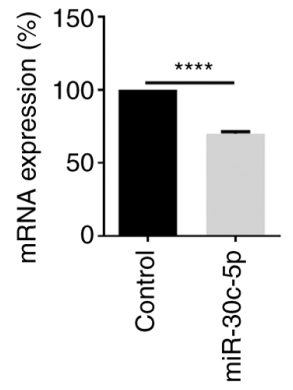

Figure 10. miRNAs regulated by TGF- $\beta 1$ reciprocally regulate the expression of genes involved in the TGF- $\beta$ signaling pathway. The plots show the expression of genes $48 \mathrm{~h}$ after the transfection of Caki-2 cells with (A) miR-181a-5p as well as miR-181b-5p, (B) miR-155-5p and (C) miR-30c-5p mimics or non-targeting control mimics. Statistical analysis was performed using t-test. ${ }^{*} \mathrm{P}<0.05 ;{ }^{* *} \mathrm{P}<0.01 ;{ }^{* * *} \mathrm{P}<0.001 ;{ }^{* * * *} \mathrm{P}<0.0001$. miRNA/miR, microRNA.

were dependent on the origins of the cell lines, the aforementioned experiments were repeated using the additional two ccRCC cell lines: KIJ265T and KIJ308T [from Dr J. Copland from Mayo Foundation for Medical Education and Research (Rochester, MN, USA)]. In accordance with the results from 786-O cells, silencing ETS1 expression decreased the proliferation of KIJ265T and KIJ308T cells. However, inhibition of BMPR 2 expression did not affect the proliferation in these cells (Fig. 9A). These results suggest that ETS1 can stimulate the proliferation of ccRCC-derived cell lines, while decreasing the proliferation of the papillary RCC-derived cell line Caki-2. To evaluate this tumor-subtype-dependent ETS1 role in RCC, its expression was measured in papillary RCC tumor samples using the publicly available TCGA data (Fig. 9B). This analysis revealed that in contrast to that in ccRCC tumors, ETS1 expression levels were significantly lower in pRCC tumors (Fig. 9C). In agreement with the data of ccRCC tumors in the present study, this TCGA data confirmed the enhanced expression of ETS1 in ccRCC tumors (Fig. 9C). These observations suggest that ETS1 serves different roles in different subtypes of RCC tumors, functioning as a tumor suppressor in papillary RCC, while potentiating proliferation in ccRCC.

BrdU assay results revealed that TGF- $\beta 1$ treatment also decreased the proliferation of all three ccRCC-derived cell lines tested (786-O, KIJ265T and KIJ308T), but increased the proliferation of Caki-2 cells (Fig. 9C). By contrast, ETS1 expression was significantly increased by TGF- $\beta 1$ treatment in all cell lines tested except for KIJ308T cells (Fig. 9C). This suggests that the effects of TGF- $\beta 1$ on the ccRCC and pRCC cell lines were mediated not only by ETS1.

TGF- $\beta$-regulated microRNAs reciprocally regulate the expression of genes involved in the TGF- $\beta$ signaling pathway.
miRNAs frequently function in regulatory feedback circuits in which genes targeted by specific miRNAs can reciprocally regulate their expression (21). Therefore, the effects of TGF- $\beta$-regulated miRNAs on the expression of genes involved in the TGF- $\beta 1$ signaling pathway were next tested. Transfection of Caki-2 cells with the miR-181a-5p mimic led to the downregulation of TGFBR1, TGFBR3, SMAD3 and SMAD7 expression, while miR-181b-5p mimic transfection inhibited the expression of SMAD3 and miR-155-5p overexpression attenuated the expression of TGFBR1 and SMAD1. By contrast, miR-30c-5p overexpression increased TGFBR3 expression but decreased the expression of SMAD1 (Fig. 10). These results verified the aforementioned observations that the analyzed miRNAs (miR-30c-5p, miR-155-5p, miR-181a-5p and $181 \mathrm{~b}-5 \mathrm{p}$ ) and genes in the TGF- $\beta 1$-signaling pathway coordinate in a regulatory feedback mechanism.

\section{Discussion}

The present study demonstrated that TGF- $\beta 1$ can regulate RCC cells proliferation while concomitantly modifying the expression of the regulator, ETS1, in addition to that of miRNAs miR-30c-5p, miR-125b-5p, miR-155-5p, miR-181a-5p and miR-181b-5p. Furthermore, that the effects of TGF- $\beta 1$ may depend on the subtype of RCC. In all three ccRCC-derived cell lines tested, TGF- $\beta 1$ attenuated their proliferation. By contrast, in the papillary RCC-derived Caki-2 cell line, TGF- $\beta 1$ stimulated proliferation. However, these actions are unlikely to be mediated by ETS1, which was found to be a consistent stimulator of ccRCC proliferation but an inhibitor of papillary RCC cell proliferation. These data were consistent with those of ETS1 expression in tumor samples of patients with RCC. In ccRCC, the expression of ETS1 was found to 
be enhanced, while in papillary RCC tumors ETS1 expression was found to be lower. This suggested that ETS1 may serve subtype-dependent roles in RCC, acting as an oncogenic protein in ccRCC but as a tumor suppressor in pRCC.

This observation of the different roles of ETS1 in the regulation of RCC physiology agreed with previous reports on the different properties of 786-O and Caki-2 cells, including proliferative changes in response to different extracellular matrix components $(22,23)$. In addition, Caki-2 and 786-O cells differ in terms of their expression profiles of hypoxia-induced factor (HIF) isoforms (24). Specifically, 786-O cells express HIF-2 $\alpha$ while lacking functional HIF-1 $\alpha$ proteins $(24,25)$. By contrast, Caki-2 cells express both isoforms of HIF- $\alpha$ (24). These two HIF isoforms serve different roles in RCC pathophysiology, with HIF- $2 \alpha$ functioning as the promoter, while HIF- $1 \alpha$ functioning as the inhibitor of tumor growth (25). This is reflected by the differential transcriptional selectivity of genes regulated by either of the HIF isoforms (25). RCC tumors expressing only HIF- $2 \alpha$ are characterized by increased proliferative behavior and are associated with poorer prognosis (26). These differences in the HIF isoform expression patterns may also influence responses to TGF- $\beta 1$ treatment. It was previously shown that TGFBR1 can interact with HIF- $1 \alpha$ and HIF- $2 \alpha$ to promote the expression of the two isoforms (27), whereas both TGF- $\beta$ and HIF-1 $\alpha$ can independently regulate the same target gene (28). The different effects of ETS1 on Caki-2 and 786-O cell proliferation are also consistent with the previously reported cell line-specific actions of ETS1 (29-32). The contrasting cellular functions of ETS1 (including responses to signaling pathways) may result from differential protein-protein interactions, specifically interactions with tissue or cell type specific transcription factors $(29,30)$. Although these findings are similar to those with the differential expression profiles of HIF in Caki-2 and 786-O cells, the possible RCC tumor subtype specific actions of TGF- $\beta 1$ and ETS1 require further exploration.

The effects of the TGF- $\beta 1$ on RCC cells appeared to be at least partially mediated by miRNAs. Treatment of RCC cells with TGF- $\beta 1$ reduced the expression of miR-30c-5p, resulting in the elevated expression of its target BMPR2. TGF- $\beta 1$ also enhanced the expression of miR-125b-5p and suppressed the expression of miR-155-5p, the two miRNAs that were found to directly target and reduce the expression of ETS1. ETS1 was previously reported to be a miR-155-5p target in invariant natural killer T lymphocytes (33) and the endothelium (34). By contrast, miR-125b-5p was found to be aETS1 regulator in vascular smooth muscle cells (35), T-cell acute leukemia (36), hepatoma cells (37) and breast cancer (38). TGF- $\beta 1$ itself stimulated the expression of ETS1, suggesting that the increased ETS1 expression levels in RCC was a result of direct TGF- $\beta 1$ activation. TGF- $\beta 1$ was previously found to increase ETS1 expression to activate the cellular communication network factor 2 (CCN2) growth factor in osteoblasts (39), whereas it can and utilizes ETS1 to activate the expression of integrin $\alpha 3$ in HepG2 cells (40).

The differences observed in the effects of miR-155 transfection on ETS1 mRNA expression resulted from diverse conditions of these experiments. In the case of results present in Fig. 6A, transfection of cells was performed in a medium supplemented with FBS, while experiments present in Fig. 6D were performed in a medium without FBS but with the addition of a high concentration of TGF- $\beta 1$ (10 ng/ml). FBS contains TGF- $\beta 1$ in the concentration of $1-2 \mathrm{ng} / \mathrm{ml}$ (41), thus in experiments present in Fig. 6D, an enhanced effect of TGF- $\beta 1$ was observed. This cytokine most likely regulates the expression of other miRNAs or transcription factors that in turn affect the expression of ETS1.

The lack of interaction between BMPR2 MRE and miR-181, but decreased BMPR2 expression after miR-181a transfection, indicated an indirect regulation between this molecules. It is possible that miR-181a might regulate the expression of transcription factors that affect BMPR2 level. This is in agreement with published results demonstrating that STAT3 is transcription factor regulating BMPR2 expression (42) while miR-181 regulates the expression of STAT3 (43). TGF- $\beta$ can regulate the expression of miRNAs by regulating several cellular processes, including transcription and post-transcriptional maturation of miRNA precursors. These TGF- $\beta 1$-mediated mechanisms mainly involve SMAD proteins, which bind to the promoters of genes encoding miRNAs to activate their transcription (44) or interact with primary miRNA transcripts, to facilitate Drosha-mediated cleavage (45). TGF- $\beta$ can also indirectly regulate miRNA expression and function through post-transcriptional regulation, including LIN28B (44) or long non-coding RNA ZEB1-AS1 (46). These two types of mechanisms can exert opposite effects on miRNA expression, so that TGF- $\beta 1$ can directly increase the expression of a given miRNA, but post-transcriptionally suppress its expression (44). Therefore, it cannot be excluded that similar regulatory mechanisms exist in RCC cells. Stimulatory effects of TGF- $\beta 1$ on the expression of miR-125b-5p in the present study are consistent with observations from a previous study on pancreatic carcinoma (44). Specifically, TGF- $\beta 1$ can induce the expression of MIR100HG, a tricistronic host gene of miR-100, miR-125b and let-7a (44). In addition, the miR-99a/100-125b tricistronic miRNAs block TGF- $\beta$ signaling by targeting the expression of several genes in the TGF- $\beta 1$ pathway, including BMPR2 and TGFBR1, both of which can be targeted by miR-125b-5p (47). This is suggestive of reciprocal feedback regulation. Reduced expression of miR-30c-5p in RCC cells treated with TGF- $\beta 1$ observed in the present study may be due to TGF- $\beta$ attenuating the maturation of miR-30c precursors, which was previously found in endothelial cells (48). In these cells, TGF- $\beta 1$ increases the expression of the miR-30c target plasminogen activator inhibitor 1 to activate tumor-associated angiogenesis (48). In addition, miR-30c-5p stimulated the expression of TGFBR3 while suppressing that of SMAD1. TGFBR3 functions as a co-receptor to present the TGF- $\beta$ ligand to type II receptors (49) the loss of which promotes tumor growth and metastatic progression in renal cancer (50). SMAD1 is a downstream effector of endoglin (51), which, similarly to TGFBR3, acts as a co-receptor in the TGF- $\beta$ pathway and confers self-renewal properties in RCC cells to promote chemoresistance (52). Since TGF- $\beta$ suppressed the expression of miR-30c-5p in the present study, increased TGF- $\beta$ expression may prevent miR-30c-5p-mediated stimulation of TGFBR3, reducing its expression in RCC tumors, thereby resulting in the promotion of RCC proliferation. Similarly, TGF- $\beta$-induced suppression of miR-30c-5p expression can possibly prevent its inhibitory effects on endoglin-SMAD1-mediated malignancy in RCC. Furthermore, TGF- $\beta 1$ was found to increase the expression of miR-181a-5p in the present study, which suppressed TGFBR3 expression. These results suggested that TGF- $\beta 1$-mediated 
regulation of miR-30c-5p and miR-181a-5p lead to decreased TGFBR3 expression in RCC tumors to facilitate cancer progression. In addition, miR-181a-5p also suppressed the expression of the TGF- $\beta 1$ signaling inhibitor SMAD7 in the present study, which may contribute to $\mathrm{RCC}$ progression $(3,53)$. Other genes that were found to be regulated by the miRNAs in the present study included TGFBR1, which was suppressed by miR-155-5p and miR-181a-5p; SMAD1, which was suppressed by miR-155-5p; and SMAD3, suppressed by miR-181a-5p and miR-181b-5p. These results suggested that TGF- $\beta$-regulated miRNAs can reciprocally regulate the expression of genes in the TGF- $\beta$ signaling pathway in RCC.

To conclude, the results of the present study indicated a complex network of TGF- $\beta 1$-mediated regulation of miRNA expression and genes involved in the malignant transformation of the kidney. TGF- $\beta 1$ differentially regulated the physiology of RCC cells, specifically by attenuating the proliferation of ccRCC-derived cell lines while stimulating the proliferation of papillary RCC-derived cells. However, these effects are not likely to be mediated by ETS1. However, the present study suggested that ETS1 may serve ambiguous roles depending on the different subtypes of RCC, where it can serve as an oncogene in ccRCC and a tumor suppressor in papillary RCC. This possibility requires further experimental verification. Proposed agents targeting the TGF- $\beta$ signaling pathway in renal cancer are currently undergoing testing in clinical trials $(54,55)$. This suggests that the expression profiling of miRNAs identified in the present study may be applied to select patients who may exhibit superior responses to such therapies. It is expected that further exploration of the detailed mechanism involved in the TGF- $\beta 1$-controlled miRNA-target gene network may give rise to novel therapeutic applications for renal cancer in the future.

\section{Acknowledgements}

The authors wish to thank Dr J. Copland from Mayo Foundation for Medical Education and Research (Rochester MN, USA) for the KIJ265T and KIJ308T cell lines and Michal Witkowski from the Department of Biochemistry and Molecular Biology, Centre of Postgraduate Medical Education (Warsaw, Poland) for support in data visualization using $\mathrm{R}$.

\section{Funding}

This research was funded by The Polpharma Scientific Foundation's grant (to JB) and National Science Center, Poland, grant no. 2018/29/B/NZ5/01211 (to APW).

\section{Availability of data and materials}

The datasets used and/or analyzed during the current study are available from the corresponding author on reasonable request.

\section{Authors' contributions}

Conceptualization of the present study was by JB and APW. Methodology by JB and validation by JB and KH. Formal analysis was performed by JB and APW, investigation by $\mathrm{KH}$, $\mathrm{BR}, \mathrm{PP}, \mathrm{KG}, \mathrm{JB}$ and AAO. Data curation was the responsibility of JB, KH, PP, APW and BR. JB and APW confirm the authenticity of all the raw data. All authors have read and agreed to the published version of the manuscript.

\section{Ethics approval and consent to participate}

Tissue samples were collected with written informed consent of each patient with approval of the Bioethical Committee of Centre of Postgraduate Medical Education (approval nos. 18/PB/2012 and 75/PB-A/2014; Warsaw, Poland).

\section{Patient consent for publication}

Not applicable.

\section{Competing interests}

The authors declare that they have no competing interests.

\section{References}

1. Ricketts CJ and Linehan WM: Multi-regional sequencing elucidates the evolution of clear cell renal cell carcinoma. Cell 173: 540-542, 2018.

2. Bharthuar A, Pandey H and Sood S: Management of metastatic renal cell carcinoma-mini review. J Kidney Cancer VHL 2: 75-83, 2015.

3. Boguslawska J, Kryst P, Poletajew S and Piekielko-Witkowska A: TGF- $\beta$ and microRNA interplay in genitourinary cancers. Cells 8: 1619, 2019.

4. Bihr S, Ohashi R, Moore AL, Rüschoff JH, Beisel C, Hermanns T, Mischo A, Corrò C, Beyer J, Beerenwinkel N, et al: Expression and mutation patterns of PBRM1, BAP1 and SETD2 mirror specific evolutionary subtypes in clear cell renal cell carcinoma. Neoplasia 21: 247-256, 2019.

5. Brugarolas J: Molecular genetics of clear-cell renal cell carcinoma. J Clin Oncol 32: 1968-1976, 2014.

6. Boguslawska J, Poplawski P, Alseekh S, Koblowska M, Iwanicka-Nowicka R, Rybicka B, Kędzierska H, Głuchowska K, Hanusek K, Tański Z, et al: MicroRNA-mediated metabolic reprograming in renal cancer. Cancers (Basel) 11: 1825, 2019.

7. Schanza LM, Seles M, Stotz M, Fosselteder J, Hutterer GC, Pichler M and Stiegelbauer V: MicroRNAs associated with Von Hippel-Lindau pathway in renal cell carcinoma: A comprehensive review. Int J Mol Sci 18: 2495, 2017.

8. Stuelten $\mathrm{CH}$ and Zhang YE: Transforming growth factor- $\beta$ : An agent of change in the tumor microenvironment. Front Cell Dev Biol 9: 764727, 2021.

9. Bogusławs ka J, Rodzik K, Popławski P, Kędzierska H, Rybicka B, Sokół E, Tański Z and Piekiełko-Witkowska A: TGF- $\beta 1$ targets a microRNA network that regulates cellular adhesion and migration in renal cancer. Cancer Lett 412: 155-169, 2018.

10. Livak KJ and Schmittgen TD: Analysis of relative gene expression data using real-time quantitative PCR and the 2(-Delta Delta C(T)) method. Methods 25: 402-408, 2001.

11. Lu TP, Lee CY, Tsai MH, Chiu YC, Hsiao CK, Lai LC and Chuang EY: miRSystem: An integrated system for characterizing enriched functions and pathways of microRNA targets. PLoS One 7: e42390, 2012.

12. Li JH, Liu S, Zhou H, Qu LH and Yang JH: starBase v2.0: Decoding miRNA-ceRNA, miRNA-ncRNA and protein-RNA interaction networks from large-scale CLIP-Seq data. Nucleic Acids Res 42: D92-D97, 2014.

13. Chen F, Chandrashekar DS, Varambally S and Creighton CJ: Pan-cancer molecular subtypes revealed by mass-spectrometry-based proteomic characterization of more than 500 human cancers. Nat Commun 10: 5679, 2019.

14. Yang L, Zou X, Zou J and Zhang G: A review of recent research on the role of MicroRNAs in renal cancer. Med Sci Monit 27: e930639, 2021.

15. Spadaccino F, Gigante M, Netti GS, Rocchetti MT, Franzin R, Gesualdo L, Castellano G, Stallone G and Ranieri E: The ambivalent role of miRNAs in carcinogenesis: Involvement in renal cell carcinoma and their clinical applications. Pharmaceuticals (Basel) 14: 322, 2021. 
16. Sun IO and Lerman LO: Urinary microRNA in kidney disease: Utility and roles. Am J Physiol Renal Physiol 316: F785-F793, 2019

17. Morizane R, Fujii S, Monkawa T, Hiratsuka K, Yamaguchi S, Homma $\mathrm{K}$ and Itoh $\mathrm{H}$ : miR-34c attenuates epithelial-mesenchymal transition and kidney fibrosis with ureteral obstruction. Sci Rep 4: 4578, 2014.

18. Boguslawska J, Kedzierska H, Poplawski P, Rybicka B, Tanski Z and Piekielko-Witkowska A: Expression of genes involved in cellular adhesion and extracellular matrix remodeling correlates with poor survival of patients with renal cancer. J Urol 195 : 1892-1902, 2016

19. Wang R, Ma Y, Yu D, Zhao J and Ma P: miR-377 functions as a tumor suppressor in human clear cell renal cell carcinoma by targeting ETS1. Biomed Pharmacother 70: 64-71, 2015.

20. Toschi A, Edelstein J, Rockwell P, Ohh M and Foster DA: HIF alpha expression in VHL-deficient renal cancer cells is dependent on phospholipase D. Oncogene 27: 2746-2753,2008

21. Ferro E, Enrico Bena C, Grigolon S and Bosia C: From endogenous to synthetic microRNA-mediated regulatory circuits: An overview. Cells 8: 1540, 2019.

22. Majo S, Courtois S, Souleyreau W, Bikfalvi A and Auguste P: Impact of extracellular matrix components to renal cell carcinoma behavior. Front Oncol 10: 625, 2020.

23. Micucci C, Matacchione G, Valli D, Orciari S and Catalano A: HIF $2 \alpha$ is involved in the expansion of CXCR4-positive cancer stem-like cells in renal cell carcinoma. Br J Cancer 113 $1178-1185,2015$

24. Shinojima T, Oya M, Takayanagi A, Mizuno R, Shimizu N and Murai M: Renal cancer cells lacking hypoxia inducible factor (HIF)-1alpha expression maintain vascular endothelial growth factor expression through HIF-2alpha. Carcinogenesis 28 : 529-536, 2007

25. Raval RR, Lau KW, Tran MG, Sowter HM, Mandriota SJ, Li JL, Pugh CW, Maxwell PH, Harris AL and Ratcliffe PJ: Contrasting properties of hypoxia-inducible factor 1 (HIF-1) and HIF-2 in von Hippel-Lindau-associated renal cell carcinoma. Mol Cell Biol 25: 5675-5686, 2005

26. Melendéz-Rodriguez F, Roche O, Sanchez-Prieto R and Aragones J: Hypoxia-inducible factor 2-dependent pathways driving Von Hippel-Lindau-deficient renal cancer. Front Oncol 8: $214,2018$.

27. Mallikarjuna P, Raviprakash TS, Aripaka K, Ljungberg B and Landström M: Interactions between TGF- $\beta$ type I receptor and hypoxia-inducible factor-alpha mediates a synergistic crosstalk leading to poor prognosis for patients with clear cell renal cell carcinoma. Cell Cycle 18: 2141-2156, 2019.

28. Katoh $M$ and Katoh M: Integrative genomic analyses of ZEB2: Transcriptional regulation of ZEB2 based on SMADs, ETS1, HIF1alpha, POU/OCT, and NF-kappaB. Int J Oncol 34: 1737-1742, 2009

29. Dittmer J: The biology of the Ets1 proto-oncogene. Mol Cancer 2 . 29, 2003.

30. Taveirne S, Wahlen S, Van Loocke W, Kiekens L, Persyn E, Van Ammel E, De Mulder K, Roels J, Tilleman L, Aumercier M, et al: The transcription factor ETS1 is an important regulator of human NK cell development and terminal differentiation. Blood 136: 288-298, 2020.

31. Morrell NW: Pulmonary hypertension due to BMPR2 mutation: A new paradigm for tissue remodeling? Proc Am Thorac Soc 3: 680-686, 2006

32. Han R, Beppu H, Lee YK, Georgopoulos K, Larue L, Li E, Weiner L and Brissette JL: A pair of transmembrane receptors essential for the retention and pigmentation of hair. Genesis 50 : 783-800, 2012

33. Burocchi A, Pittoni P, Tili E, Rigoni A, Costinean S, Croce CM and Colombo MP: Regulated expression of miR-155 is required for iNKT cell development. Front Immunol 6: 140, 2015.

34. Zhu N, Zhang D, Chen S, Liu X, Lin L, Huang X, Guo Z, Liu J, Wang Y, Yuan W and Qin Y: Endothelial enriched microRNAs regulate angiotensin II-induced endothelial inflammation and migration. Atherosclerosis 215: 286-293, 2011.

35. Wen P, Cao H, Fang L, Ye H, Zhou Y, Jiang L, Su W, Xu H, $\mathrm{He} \mathrm{W}$, Dai $\mathrm{C}$ and Yang J: miR-125b/Ets1 axis regulates transdifferentiation and calcification of vascular smooth muscle cells in a high-phosphate environment. Exp Cell Res 322: 302-312, 2014

36. Renou L, Boelle PY, Deswarte C, Deswarte C, Spicuglia S, Benyoucef A, Calvo J, Uzan B, Belhocine M, Cieslak A, et al: Homeobox protein TLX3 activates miR-125b expression to promote T-cell acute lymphoblastic leukemia. Blood Adv 1: 733-747, 2017.
37. Zeng JF, Zeng ZL, Zhang K, Zhao Y, Liu YM, Chen JJ, Tong H, Wei DH, Jiang ZS and Wang Z: miR-23b-3p and miR-125b-5p downregulate apo(a) expression by targeting Ets1 in HepG2 cells. Cell Biol Int 42: 313-323, 2018

38. Zhang Y, Yan LX, Wu QN, Du ZM, Chen J, Liao DZ, Huang MY, Hou JH, Wu QL, Zeng MS, et al: miR-125b is methylated and functions as a tumor suppressor by regulating the ETS1 proto-oncogene in human invasive breast cancer. Cancer Res 71: $3552-3562,2011$

39. Geisinger MT, Astaiza R, Butler T, Popoff SN, Planey SL and Arnott JA: Ets-1 is essential for connective tissue growth factor (CTGF/CCN2) induction by TGF-beta1 in osteoblasts. PLoS One 7: e35258, 2012

40. Katabami K, Mizuno H, Sano R, Saito Y, Ogura M, Itoh S and Tsuji T: Transforming growth factor-betal upregulates transcription of alpha3 integrin gene in hepatocellular carcinoma cells via Ets-transcription factor-binding motif in the promoter region. Clin Exp Metastasis 22: 539-548, 2005.

41. Oida T and Weiner HL: Depletion of TGF- $\beta$ from fetal bovine serum. J Immunol Methods 362: 195-198, 2010.

42. Bisserier M, Katz MG, Bueno-Beti C, Brojakowska A, Zhang S, Gubara S, Kohlbrenner E, Fazal S, Fargnoli A, Dorfmuller P, et al: Combination therapy with STAT3 inhibitor enhances SERCA2a-induced BMPR2 expression and inhibits pulmonary arterial hypertension. Int J Mol Sci 22: 9105, 2021.

43. Assmann J, Leon LG, Stavast CJ, van den Bogaerdt SE, Schilperoord-Vermeulen J, Sandberg Y, Bellido M, Erkeland SJ, Feith DJ, Loughran TP Jr and Langerak AW: miR-181a is a novel player in the STAT3-mediated survival network of TCR $\alpha \beta^{+}$ $\mathrm{CD}^{+} \mathrm{T}$ large granular lymphocyte leukemia. Leukemia: Dec 6, 2021 (Epub ahead of print).

44. Ottaviani S, Stebbing J, Frampton AE, Zagorac S, Krell J, de Giorgio A, Trabulo SM, Nguyen VT, Magnani L, Feng H, et al: TGF- $\beta$ induces miR-100 and miR-125b but blocks let-7a through LIN28B controlling PDAC progression. Nat Commun 9: 1845, 2018.

45. Davis BN, Hilyard AC, Nguyen PH, Lagna G and Hata A: Smad proteins bind a conserved RNA sequence to promote microRNA maturation by Drosha. Mol Cell 39: 373-384, 2010.

46. Lv SY, Shan TD, Pan XT, Tian ZB, Liu XS, Liu FG, Sun XG, Xue HG, Li XH, Han Y, et al: The lncRNA ZEB1-AS1 sponges miR-181a-5p to promote colorectal cancer cell proliferation by regulating Wnt/ $\beta$-catenin signaling. Cell Cycle 17: 1245-1254, 2018.

47. Emmrich S, Rasche M, Schoning J, Schöning J, Reimer C, Keihani S, Maroz A, Xie Y, Li Z, Schambach A, et al: miR-99a/100 125b tricistrons regulate hematopoietic stem and progenitor cell homeostasis by shifting the balance between TGF $\beta$ and Wnt signaling. Genes Dev 28: 858-874, 2014.

48. McCann JV, Xiao L, Kim DJ, Khan OF, Kowalski PS, Anderson DG, Pecot CV, Azam SH, Parker JS, Tsai YS, et al: Endothelial miR-30c suppresses tumor growth via inhibition of TGF- $\beta$-induced Serpine1. J Clin Invest 129: 1654-1670, 2019.

49. Bilandzic M and Stenvers KL: Betaglycan: A multifunctional accessory. Mol Cell Endocrinol 339: 180-189, 2011.

50. Nishida J, Miyazono K and Ehata S: Decreased TGFBR3/betaglycan expression enhances the metastatic abilities of renal cell carcinoma cells through TGF- $\beta$-dependent and -independent mechanisms. Oncogene 37: 2197-2212, 2018.

51. Dallas NA, Samuel S, Xia L, Fan F, Gray MJ, Lim SJ and Ellis LM: Endoglin (CD105): A marker of tumor vasculature and potential target for therapy. Clin Cancer Res 14: 1931-1937, 2008.

52. Hu J, Guan W, Liu P, Dai J, Tang K, Xiao H, Qian Y, Sharrow AC, Ye Z, Wu L and Xu H: Endoglin is essential for the maintenance of self-renewal and chemoresistance in renal cancer stem cells. Stem Cell Reports 9: 464-477, 2017.

53. Zhai W, Li S, Zhang J, Chen Y, Ma J, Kong W, Gong D, Zheng J, Xue W and Xu Y: Sunitinib-suppressed miR-452-5p facilitates renal cancer cell invasion and metastasis through modulating SMAD4/SMAD7 signals. Mol Cancer 17: 157, 2018.

54. Hahn AW, Pal SK and Agarwal N: Targeting endoglin to treat metastatic renal cell carcinoma: Lessons from osler-weber-rendu syndrome. Oncologist 24: 143-145, 2019.

55. Choueiri TK, Michaelson MD, Posadas EM, Sonpavde GP, McDermott DF, Nixon AB, Liu Y, Yuan Z, Seon BK, Walsh M, et al: An open label phase Ib dose escalation study of TRC105 (anti-endoglin antibody) with axitinib in patients with metastatic renal cell carcinoma. Oncologist 24: 202-210, 2019.

This work is licensed under a Creative Commons Attribution-NonCommercial-NoDerivatives 4.0 International (CC BY-NC-ND 4.0) License. 